ACG THE AMERICAN

\title{
Evolution after anti-TNF discontinuation in patients with inflammatory bowel disease: a multicenter long-term follow-up study
}

\begin{tabular}{|r|l|}
\hline Journal: & American Journal of Gastroenterology \\
\hline Manuscript ID & AJG-16-0890.R1 \\
\hline Manuscript Type: & Original Contributions \\
\hline Keywords: & $\begin{array}{l}\text { Inflammatory Bowel Disease, Crohn's Disease, ulcerative colitis, anti-TNF, } \\
\text { Infliximab, Adalimumab, discontinuation, withdrawal }\end{array}$ \\
\hline Manuscript Section: & Inflammatory bowel disease \\
\hline \multicolumn{2}{|l}{} \\
\hline
\end{tabular}




\section{EVOLUTION AFTER ANTI-TNF DISCONTINUATION IN PATIENTS WITH INFLAMMATORY BOWEL DISEASE: A MULTICENTER LONG-TERM FOLLOW-UP STUDY}

SHORT TITLE: Evolution after anti-TNF discontinuation in IBD patients

\section{AUTHORS}

MJ. Casanova ${ }^{1}$, M. Chaparro ${ }^{1}$, V. García-Sánchez ${ }^{2}$, O. Nantes ${ }^{3}$, E. Leo ${ }^{4}$, M. Rojas-Feria ${ }^{5}$, A. Jauregui-Amezaga ${ }^{6}$, S. García-López ${ }^{7}$, JM. Huguet ${ }^{8}$, F. Arguelles-Arias ${ }^{9}$, M. Aicart ${ }^{10}$, I. Marín-Jiménez $^{11}$, M. Gómez-García ${ }^{12}, \mathrm{~F}$. Muñoz ${ }^{13}$, M. Esteve ${ }^{14}$, L. Bujanda $^{15}$, X. Cortés ${ }^{16}$, J.

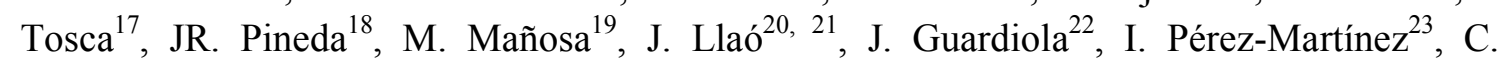
Muñoz $^{24}$, Y. González-Lama ${ }^{25}$, J. Hinojosa ${ }^{26}$, JM. Vázquez ${ }^{27}$, MP. Martinez-Montiel $^{28}$, GE. Rodríguez $^{29}$, R. Pajares ${ }^{30}$, MF. García-Sepulcre ${ }^{31}$, A. Hernández-Martínez ${ }^{32}$, JL. PérezCalle $^{33}$, B. Beltrán ${ }^{34}$ D. Busquets ${ }^{35}$, L. Ramos ${ }^{36}$, F. Bermejo ${ }^{37}$, J. Barrio ${ }^{38}$, M. Barreiro-de Acosta $^{39}$, O. Roncedo ${ }^{40}$, X. Calvet ${ }^{41}$, D. Hervías ${ }^{42}$, F. Gomollón ${ }^{43}$, M. DomínguezAntonaya $^{44}$, G. Alcaín ${ }^{45}$, B. Sicilia ${ }^{46}$, C. Dueñas ${ }^{47}$, A. Gutiérrez ${ }^{48}$, R. Lorente-Poyatos ${ }^{49}$, M. Domínguez $^{50}$, S. Khorrami ${ }^{51}$, C. Muñoz ${ }^{52}$, C. Taxonera ${ }^{53}$, A. Rodríguez-Pérez ${ }^{54}$, A. Ponferrada $^{55}$, M. Van Domselaar ${ }^{56}$, ML. Arias-Rivera ${ }^{57}$, O. Merino ${ }^{58}$, E. Castro ${ }^{59}$, JM. Marrero $^{60}$, M. Martín-Arranz ${ }^{61}$, B. Botella ${ }^{62}$, L. Fernández-Salazar ${ }^{63}$, D. Monfort ${ }^{64}$, V. Opio ${ }^{65}$, A. García-Herola ${ }^{66}$, M. Menacho ${ }^{67}$, P. Ramírez-de la Piscina ${ }^{68}$, D. Ceballos ${ }^{69}$, P. Almela ${ }^{70}$, M. Navarro-Llavat $^{71}$, V. Robles-Alonso ${ }^{72}$, AB. Vega-López ${ }^{73}$, I. Moraleja ${ }^{74}$, MT. Novella ${ }^{75}$, C. Castaño-Milla $^{76}$, A. Sánchez-Torres ${ }^{77}$, JM. Benítez ${ }^{2}$, C. Rodríguez ${ }^{3}$, L. Castro ${ }^{9}$, E. Garrido ${ }^{10}$, E. Domènech ${ }^{19}$, E. García-Planella ${ }^{20}$ and JP. Gisbert ${ }^{1}$

Gastroenterology Departments from: ${ }^{1}$ Hospital Universitario de La Princesa, Instituto de Investigación Sanitaria Princesa (IIS-IP) and Centro de Investigación Biomédica en Red de Enfermedades Hepáticas y Digestivas (CIBEREHD), Madrid; ${ }^{2}$ Hospital Universitario Reina Sofía, Córdoba; ${ }^{3}$ Complejo Hospitalario de Navarra and Instituto de Investigación Sanitaria de Navarra (IdiSNA), Pamplona; ${ }^{4}$ Hospital Universitario Virgen del Rocío, Sevilla; ${ }^{5}$ Hospital Universitario de Valme, and CIBEREHD, Sevilla; ${ }^{6}$ Hospital Clínic i Provincial, and CIBEREHD, Barcelona; ${ }^{7}$ Hospital Universitario Miguel Servet, Zaragoza; ${ }^{8}$ Consorcio Hospital General Universitario de Valencia, Valencia; ${ }^{9}$ Hospital Universitario Virgen Macarena, Sevilla; ${ }^{10}$ Hospital Universitario Ramón y Cajal, Madrid; ${ }^{11}$ Hospital Universitario Gregorio Marañón and Instituto de Investigación Sanitaria Gregorio Marañón (IiSGM), Madrid; ${ }^{12}$ Hospital Universitario Virgen de las Nieves, Granada; ${ }^{13}$ Complejo Universitario de León, León; ${ }^{14}$ Hospital Universitario Mutua Terrassa, Terrassa, and CIBEREHD; ${ }^{15}$ Hospital Universitario de Donostia, Instituto Biodonostia, Universidad del País Vasco UPV/EHU, and CIBEREHD, Donostia; ${ }^{16}$ Hospital de Sagunto, Valencia; ${ }^{17}$ Hospital Clínico Valencia, Valencia; ${ }^{18}$ Complejo Hospitalario Universitario de Vigo, Vigo, ${ }^{19}$ Hospital Universitari Germans Trias i Pujol, Badalona, and CIBEREHD; ${ }^{20}$ Hospital de la Santa Creu I Sant Pau, Barcelona; ${ }^{21}$ Hospital Sant Joan de Deu, Manresa; ${ }^{22}$ Hospital Universitario de Bellvitge, Barcelona; ${ }^{23}$ Hospital Universitario Central de Asturias, Oviedo; ${ }^{24}$ Hospital de Basurto, Bilbao; ${ }^{25}$ Hospital Universitario Puerta de Hierro, Madrid; ${ }^{26}$ Hospital de Manises, Valencia; ${ }^{27}$ Hospital Juan Ramón Jiménez, Huelva; ${ }^{28}$ Hospital Universitario Doce de Octubre, Madrid; 
${ }^{29}$ Hospital Universitario Nuestra Señora de la Candelaria, Santa Cruz de Tenerife; ${ }^{30}$ Hospital Universitario Infanta Sofía, Madrid; ${ }^{31}$ Hospital General Universitario de Elche, Alicante; ${ }^{32}$ Hospital Torrecárdenas, Almería; ${ }^{33}$ Hospital Universitario Fundación de Alcorcón, Madrid; ${ }^{34}$ Hospital Universitario La Fe, Valencia, and CIBEREHD; ${ }^{35}$ Hospital Universitari de Girona Dr. Josep Trueta, Girona; ${ }^{36}$ Hospital Universitario de Canarias, La Laguna; ${ }^{37}$ Hospital Universitario de Fuenlabrada, Madrid; ${ }^{38}$ Hospital Universitario Río Hortega, Valladolid; ${ }^{39}$ Hospital Clínico Universitario de Santiago de Compostela, Santiago de Compostela; ${ }^{40}$ Hospital Villafranca de los Caballeros, Toledo; ${ }^{41}$ Hospital de Sabadell, Corporació Sanitària Universitària Parc Taulí, Sabadell, and CIBEREHD; ${ }^{42}$ Hospital Virgen de Altagracia, Ciudad Real; ${ }^{43}$ Hospital Clínico Lozano Blesa, Zaragoza, Instituto de Investigación Sanitaria Aragón (IIS Aragón), and CIBEREHD; ${ }^{44}$ Hospital Universitario de Móstoles; ${ }^{45}$ Hospital Virgen de la Victoria, Málaga; ${ }^{46}$ Hospital Universitario de Burgos, Burgos; ${ }^{47}$ Hospital Universitario San Pedro Alcántara, Cáceres; ${ }^{48}$ Hospital General Universitario de Alicante, Alicante, and CIBEREHD; ${ }^{49}$ Hospital General de Ciudad Real, Ciudad Real; ${ }^{50}$ Hospital General San Jorge, Huesca; ${ }^{51}$ Hospital Universitario Son Espases, Palma de Mallorca; ${ }^{52}$ Hospital Virgen de la Salud, Toledo; ${ }^{53}$ Hospital Universitario Clínico San Carlos and Instituto de Investigación del Hospital Clínico San Carlos (IdISSC), Madrid; ${ }^{54}$ Hospital Universitario De Salamanca, Salamanca; ${ }^{55}$ Hospital Universitario Infanta Leonor, Madrid; ${ }^{56}$ Hospital de Torrejón de Ardoz, Madrid; ${ }^{57}$ Hospital Universitario Severo Ochoa, Madrid; ${ }^{58}$ Hospital Universitario Cruces, Barakaldo; ${ }^{59}$ Hospital Lucus Augusti, Lugo; ${ }^{60}$ Hospital Universitario Insular de Gran Canaria, Las Palmas de Gran Canaria; ${ }^{61}$ Hospital Universitario La Paz, Madrid; ${ }^{62}$ Hospital Universitario Infanta Cristina, Madrid; ${ }^{63}$ Hospital Clínico Universitario de Valladolid, Valladolid; ${ }^{64}$ Consorci Sanitari Terrassa, Terrassa; ${ }^{65}$ Hospital Universitario de Getafe, Madrid; ${ }^{66}$ Hospital Marina Baixa, Alicante; ${ }^{67}$ Hospital Joan XXIII, Tarragona; ${ }^{68}$ Hospital Universitario de Álava, Vitoria; ${ }^{69}$ Hospital Universitario Dr. Negrín, Las Palmas de Gran Canaria; ${ }^{70}$ Hospital General Universitario de Castellón, Castellón; ${ }^{71}$ Hospital de Sant Joan Despí Moisès Broggi, Sant Joan Despí; ${ }^{72}$ Hospital Universitari Vall d'Hebron, Barcelona; ${ }^{73}$ Hospital de Viladecans, Barcelona; ${ }^{74}$ Hospital de Galdakao-Usansolo, Galdakao; ${ }^{75}$ Hospital Can Misses, Eivissa; ${ }^{76}$ Hospital Universitario Rey Juan Carlos, Madrid; ${ }^{77}$ Hospital Virgen de la Arrixaca, Murcia, Spain.

\section{ABBREVIATIONS}

Anti-tumor necrosis factor- $\alpha$ (anti-TNF), confidence interval (CI), Crohn's disease (CD), inflammatory bowel disease (IBD), ulcerative colitis (UC), immunomodulators (IMMs), 5aminosalicylates (5-ASA), magnetic resonance imaging (MRI), hazard ratio (HR).

\section{KEY WORDS}

Inflammatory bowel disease, Crohn's disease, ulcerative colitis, anti-TNF, infliximab, adalimumab, discontinuation, withdrawal.

\section{CORRESPONDENCE}

Javier P. Gisbert, M.D. Gastroenterology Unit. La Princesa Hospital. Diego de León, 62. 28006 Madrid, Spain. Tel.: 34-913093911; Fax: 34-914022299. E-mail:

javier.p.gisbert@gmail.com 


\section{STUDY HIGHLIGHTS}

Current Knowledge

- The risk of relapse after anti-TNF withdrawal are not well known.

- The variables that impact clinical course after withdrawal are not well known.

- The efficacy and safety of retreatment with the same anti-TNF drug in patients who relapse seem to be high.

- Currently available data are insufficient to make recommendations on when anti-TNF therapy can be stopped.

What is new here

- Approximately half of the patients who discontinued anti-TNF agents because of clinical remission relapse after discontinuation.

- Treatment with ADA, elective discontinuation of anti-TNF drugs, and discontinuation due to adverse events increase the risk of relapse.

- Treatment with IMMs and older age at discontinuation are associated with a lower risk of relapse.

- Discontinuation of anti-TNF therapy cannot be universally recommended. However, some patients can stop anti-TNF therapy safely and remain in remission for long periods. 


\section{SUMMARY}

AIMS: To assess the risk of relapse after discontinuation of anti-TNF drugs in patients with inflammatory bowel disease, to identify the factors associated with relapse, and to evaluate the response to and safety of retreatment with the same anti-TNF after relapsing.

METHODS: Retrospective, observational, multicentre study. Patients with Crohn's disease or ulcerative colitis who had been treated with anti-TNFs and in whom these drugs were discontinued after clinical remission was achieved were included.

RESULTS: 1,055 patients were included. The cumulative incidence of relapse was 44\%: $24 \%$ at 1 year, $38 \%$ at 2 years, $46 \%$ at 3 years, and $56 \%$ at 5 years after anti-TNF discontinuation. The incidence rate of relapse was $18 \%$ per patient-year. The variables associated with a higher risk of relapse were treatment with adalimumab vs. infliximab $(\mathrm{HR}=1.29 ; 95 \% \mathrm{CI}=1.03-1.60)$ and elective discontinuation of anti-TNFs $(\mathrm{HR}=1.82 ; 95 \% \mathrm{CI}=1.19-2.79) \quad$ or discontinuation due to adverse events $(\mathrm{HR}=1.95 ; 95 \% \mathrm{CI}=1.22-3.12)$ vs. a top-down strategy. Treatment with immunomodulators after discontinuation $(\mathrm{HR}=0.70 ; 95 \% \mathrm{CI}=0.57-0.88)$ and age $(\mathrm{HR}=0.99 ; 95 \% \mathrm{CI}=0.98-0.99)$ were associated with a lower risk of relapse. Retreatment of relapse with the same anti-TNF was effective (88\% responded) and safe.

CONCLUSIONS: The incidence rate of relapse after anti-TNF discontinuation in patients with inflammatory bowel disease who were in remission was $18 \%$ per patient-year. Treatment with adalimumab, the elective discontinuation of anti-TNFs, or discontinuation of anti-TNFs due to adverse events (vs. top-down strategy) increased the risk of relapse. Older age and maintenance treatment with immunomodulators were associated with a lower risk of relapse. Retreatment with the same anti-TNF drug was effective and safe. 


\section{INTRODUCTION}

Anti-tumour necrosis factor- $\alpha$ (anti-TNF) drugs are effective in inducing and maintaining remission in patients with inflammatory bowel diseases (IBD), namely, Crohn's disease (CD) and ulcerative colitis (UC) ${ }^{1}$. This effectiveness is associated with mucosal healing, improved quality of life, fewer hospitalizations, and reduced need for surgical procedures ${ }^{1-4}$.

Discontinuation of anti-TNF treatment can be considered once remission has been achieved. The decision to discontinue anti-TNF drugs in patients in remission depends on several factors, such as the cost of the medications, the potential but serious adverse effects, and the outcome following elective withdrawal ${ }^{5}$. Once it has been decided that the drug is to be withdrawn, the optimal time for doing so must be established ${ }^{6}$.

Studies evaluating this strategy are mostly single-cohort designs, and most of them include a small number of patients and have a short follow-up period ${ }^{7}$. Therefore, the risk of relapse after withdrawal of anti-TNF medication and the variables that impact clinical course after withdrawal are not well known. Data from small observational studies of patients who discontinued anti-TNF therapy after having achieved clinical remission show that the range of relapse rates is wide ${ }^{8-14}$.

The retreatment with the same anti-TNF drug in patients who relapse after the initial withdrawal have been reported to be apparently successful and safe $\mathrm{e}^{12,15-17}$, and these factors are essential before deciding whether to discontinue anti-TNF therapy. However, there are many concerns relating to discontinuation of anti-TNF therapy in IBD patients that include not only the risk of relapse, but the possible loss of efficacy when the drug is restarted, the risk of infusion reactions and other adverse events at retreatment, and, finally, the possibility of losing therapeutic options. Therefore, currently available data are insufficient to make recommendations on when, if ever, anti-TNF therapy can be stopped in patients with IBD. 
The aims of the present study were to assess the risk of relapse after discontinuation of antiTNF therapy, to identify the factors associated with relapse, to know the rate of response to retreatment with the same anti-TNF drug after relapsing, and to evaluate the safety of retreatment with these drugs. 


\section{METHODS}

\section{Study population}

The present study was a multicentre, observational, retrospective study conducted at 78 Spanish centres. The study population comprised patients diagnosed with CD or UC who had been treated with anti-TNF agents (infliximab [IFX] or adalimumab [ADA]) to induce remission and in whom these drugs had been discontinued after clinical remission was achieved. The reasons for discontinuation of anti-TNF treatment were as follows: elective decision (by the physician and/or by the patient), onset of adverse events, and early introduction of thiopurines combined with an anti-TNF agent in order to induce clinical remission of IBD in patients who were naïve to immunosuppressive therapy (top-down strategy). The minimum requirement for all patients was to have received induction treatment with anti-TNF drugs. The patients were followed for a minimum of 6 months after stopping treatment. Patients who had been treated with anti-TNF drugs for reasons other than IBD or with less than 6 months of follow-up after discontinuation was excluded. If the patients had more than one attempt to stop the anti-TNF treatment, only the first attempt to discontinue this drug was included in analysis.

\section{Ethical aspects}

The study was approved by the respective institutional ethics review boards, and was conducted according to the Declaration of Helsinki and Good Clinical Practice guidelines.

\section{Data collection}

All clinical, endoscopic, and radiological data were obtained from medical records. The data collected included demographic data, duration of IBD, smoking habits, previous surgery 
for IBD, and previous IBD treatments (eg, immunosuppressants). Clinical, endoscopic, laboratory, and radiological data were collected at 3 different times during follow-up: at discontinuation of the anti-TNF drug, when the patient relapsed (if this occurred), and at the last follow-up visit. It was considered that the patient had an endoscopy or a MRI at the moment of withdrawal if these procedures were performed within 30 days before anti-TNF discontinuation. Information about the response to treatment after re-introduction of anti-TNF therapy in relapsing patients and occurrence of adverse events after reintroduction were also recorded.

Study data were collected and managed using REDCap electronic data capture tools hosted at Asociación Española de Gastroenterología (AEG; www.aegastro.es) ${ }^{18}$. AEG is a non-profit Scientific and Medical Society focused on Gastroenterology, and it provided this service free of charge, with the sole aim of promoting independent investigator driven research. REDCap (Research Electronic Data Capture) is a secure, web-based application designed to support data capture for research studies, providing 1) an intuitive interface for validated data entry; 2) audit trails for tracking data manipulation and export procedures; 3) automated export procedures for seamless data downloads to common statistical packages; and 4) procedures for importing data from external sources.

\section{Definitions}

Clinical remission: For luminal $\mathrm{CD}$, remission was defined as a Harvey-Bradshaw index score $\leq 4$ points $^{19}$. For UC, remission was defined as a partial Mayo score $\leq 2$ points $^{20}$. In the case of perianal disease, remission was defined as the absence of fistula drainage despite gentle finger compression (Fistula Drainage Assessment score) ${ }^{21}$. Given the retrospective nature of the study, Harvey-Bradshaw index and partial Mayo score were estimated after reviewing the medical records. 
Endoscopic inflammation: In the case of luminal CD, endoscopic activity was classified as mild, moderate, severe, or mucosal healing, as judged by the investigators based on the findings in the endoscopy report.

Given the retrospective design of the study, it was not feasible to calculate endoscopic scores based on the endoscopy records. The Rutgeerts index was used to categorize the severity of post-surgical recurrence ${ }^{22}$. Endoscopic inflammation in UC patients was classified using the endoscopic subscore of the Mayo index, that was applied retrospectively to individual patient reports ${ }^{23}$.

Radiological remission: For perianal CD, the disease was considered to be in remission if pelvic magnetic resonance imaging $(\mathrm{MRI})$ demonstrated that the perianal fistulas tracts showed no signs of activity and were without local complications. In the case of luminal CD patients, the disease was considered to be inactive if the abdominal MRI did not show contrast enhancement of the wall, oedema, or ulcers.

Relapse: As this is a retrospective study, relapse was defined as the onset of documented clinical, biochemical, endoscopic, or radiological activity leading to a therapeutic intervention, namely, escalation or modification of medical therapy or surgery for disease control.

Response to re-treatment: In patients with luminal $\mathrm{CD}$, remission was defined as a Harvey-Bradshaw index $\leq 4$ points: a partial response was defined as a decrease $\geq 3$ points from baseline. In fistulising $\mathrm{CD}$, remission was defined as cessation of spontaneous fistula drainage and lack of drainage after gentle finger compression, while a decrease from baseline in the number of open draining fistulae of $\geq 50 \%$ or a reduction in fistula drainage were considered partial response. In UC patients, remission was defined as a partial Mayo score $\leq 2$ points, whereas a decrease of $\geq 3$ points from baseline was considered a partial response. Response to retreatment with anti-TNF therapy was evaluated at 2 time points: 14 weeks 
(initial response) and the end of follow-up (final response).

\section{Statistical analysis}

The descriptive analysis of quantitative variables included the mean and standard deviation or the median and interquartile range, depending on whether the variables were normally distributed or not. For the categorical variables, the percentage and the $95 \%$ confidence intervals (95\% CIs) were provided. Comparisons between means were performed using the $t$ test for independent samples. Categorical variables were compared using the $\chi^{2}$ test and the Fisher exact test or the Wilcoxon rank-sum test according to the distribution of data. Statistical significance was set at $P<0.05$.

Long-term maintenance of remission was estimated using Kaplan-Meier curves. Survival curves assessing the impact of several variables on long-term remission were compared using the log-rank test. A Cox regression model was constructed to identify predictive factors for relapse. All the variables that reached statistical significance in the univariate analysis and those that were considered clinically relevant were included in the multivariate analysis. The dependent variable was the risk of relapse after discontinuation of anti-TNF therapy. The independent variables were: type of IBD (CD and UC), gender, age at discontinuation (included as a continuous variable), surgery due to IBD, current smoking habit, type of antiTNF drug received (IFX or ADA), duration of anti-TNF treatment, reasons for anti-TNF discontinuation (elective discontinuation, discontinuation due to adverse events, and discontinuation as a part of a top-down strategy), and treatment with IMMs after discontinuation of anti-TNF therapy.

The results were expressed as hazard ratios (HRs) with their corresponding 95\% CIs. 


\section{RESULTS}

\section{Study population}

The study population comprised 1,055 patients who discontinued anti-TNF drugs after achieving clinical remission and met the inclusion criteria. The median follow-up time after discontinuation was 19 (6-176) months. The main characteristics of the patients are summarized in table 1. Most patients (74\%) had received IFX. The reasons for discontinuation were elective decision (75\%), adverse events (18\%), and remission after undergoing a top-down strategy (7\%). The disease duration in patients undergoing a top-down strategy was shorter than in both elective discontinuation and adverse event groups $(9.8$ months, 11.9 months, and 13.1 months, respectively; $\mathrm{p}<0.0001)$. The median duration of antiTNF therapy in the top-down group was shorter than in the other two groups (4 months, 21 months, and 14 months, respectively; $\mathrm{p}<0.0001)$.

Seventy-two patients treated with IFX received only induction therapy [elective discontinuation group: 30/719 (4\%) patients; adverse events group: 12/174 (7\%) patients; and top-down group: 30/68 (44\%) patients]. All the patients treated with ADA received induction and maintenance therapy. Endoscopy findings at discontinuation were available in 474 patients (45\%); of these, endoscopy findings were normal (ie, no activity was detected) in 419 (88\%). In the remaining 55 patients (12\%), endoscopic activity was mild in $38(69 \%)$. After discontinuation of anti-TNF drugs, $68 \%$ of patients received therapy with immunomodulators (IMMs) (thiopurines or methotrexate).

A total of 460 patients had a normal endoscopy or a normal MRI at the moment of antiTNF withdrawal. The main characteristics of this subgroup of patients are summarized in table 2. 


\section{Evolution after discontinuation of anti-TNF therapy}

The incidence of relapse was $18 \%$ per patient-year (95\% CI=17\%-20\%). The median time to relapse after discontinuation was 11 (1-140) months, and the cumulative incidence of relapse was $44 \%(95 \% \mathrm{CI}=41 \%-46 \%): 15 \%$ at 6 months, $24 \%$ at 1 year, $38 \%$ at 2 years, $46 \%$ at 3 years, and $56 \%$ at 5 years after discontinuation. The cumulative incidence of relapse during follow-up is shown in figure 1a.

\section{Evolution by type of IBD}

In $\mathrm{CD}$ patients, the incidence of relapse was $19 \%$ per patient-year $(95 \% \mathrm{CI}=17-21 \%)$, while in $\mathrm{UC}$ patients the relapse rate was $17 \%$ per patient-year $(95 \% \mathrm{CI}=15-20 \%)$. Type of IBD was not associated with the risk of relapse $(\mathrm{p}=0.1)$. The cumulative incidence of relapse by type of IBD is shown in figures $1 \mathrm{~b}$ and $1 \mathrm{c}$.

The incidence rate of relapse was $17 \%$ per patient-year $(95 \% \mathrm{CI}=15-18 \%)$ when the analysis considered only patients receiving IMMs after discontinuation, and 26\% per patientyear $(95 \% \mathrm{CI}=22-30 \%)$ when the analysis considered only patients who did not continue the treatment with IMMs. Among patients who maintained IMMs after discontinuation, the cumulative incidence of relapse was $21 \%$ at 1 year, $35 \%$ at 2 years, $43 \%$ at 3 years, and $53 \%$ at 5 years. From the $32 \%$ of patients who did not receive IMMs after withdrawal, 195 had CD. Of these, $110(56 \%)$ patients relapsed. The incidence rate of relapse in this group of patients was $28 \%$ per patient-year (95\%CI $24-33 \%$ ). On the other hand, the incidence rate of relapse in CD patients who were under IMMs after withdrawal was $17 \%$ per patient-year (95\%CI 15-19\%). Patients who relapsed within 3 months of stopping the anti-TNF therapy (early relapse) were more often female $(64 \%$ vs. $51 \%, \mathrm{p}=0.03)$, and had received less frequently treatment with IMMs after the withdrawal of the anti-TNF $(56 \%$ vs. $68 \%$, p $=$ $0.04)$ 


\section{Evolution in patients in deep remission}

In patients in deep remission, the incidence rate of relapse was $19 \%$ per patient-year (95\%CI, 17-22\%): 19\% per patient-year in CD (95\%CI, 16-22\%), and 19\% per patient-year in UC $(95 \% \mathrm{CI}, 15-24 \%)$. The relapse rate after 1 year of discontinuation was $22 \%$ in CD patients and $20 \%$ in UC patients.

\section{Predictors of relapse after discontinuation of anti-TNF therapy}

The univariate analysis showed that gender, treatment with IMMs after discontinuation of anti-TNF therapy, type of anti-TNF drug received, and reasons for discontinuation (elective discontinuation, discontinuation due to adverse events, and discontinuation as part of a topdown strategy) were the only variables associated with the risk of relapse after discontinuation (Figures 2 and 3). No statistical differences were observed in the risk of relapse after discontinuation between patients who maintained thiopurines and patients who continued methotrexate ( $41 \%$ vs. $45 \%$; $>0.05)$.

In the multivariate analysis (table 3), the variables associated with a higher risk of relapse were treatment with $\mathrm{ADA}$ vs. IFX $(\mathrm{HR}=1.29,95 \% \mathrm{CI}=1.03-1.6)$, elective discontinuation (vs. discontinuation as part of a top-down strategy; $\mathrm{HR}=1.82,95 \% \mathrm{CI}=1.19-2.79$ ), and discontinuation due to adverse events (vs. the discontinuation as part of a top-down strategy; $\mathrm{HR}=1.95,95 \% \mathrm{CI}=1.22-3.12$ ). Treatment with IMMs (vs. no treatment) after discontinuation and older age at discontinuation $(\mathrm{HR}=0.99,95 \% \mathrm{CI}=0.98-0.99)$ were associated with a lower risk of relapse $(\mathrm{HR}=0.7,95 \% \mathrm{CI}=0.57-0.88)$. Gender, type of $\mathrm{IBD}$, current smoking habit, prior surgery related to IBD, duration of anti-TNF treatment, and previous treatment with an anti-TNF drug had no impact on the risk of relapse. 


\section{Predictors of relapse by type of IBD}

A subanalysis was performed in patients with $\mathrm{UC}$ and $\mathrm{CD}$. In UC, none of the factors was statistically significant. In CD, disease localization (colonic vs. ileal) and disease behaviour (stricturing vs. inflammatory) were associated with the risk of relapse. Moreover, the variables that were significant in the general multivariate analysis were also significant in this subanalysis (table 4), adjusted by the duration of anti-TNF treatment.

A sensitivity analysis was performed with the patients who maintained IMMs after discontinuation of anti-TNF. Older age at discontinuation was independently associated with a lower risk of relapse $(\mathrm{HR}=0.98,95 \% \mathrm{CI}=0.97-9.98)$. On the other hand, elective discontinuation (vs. discontinuation as part of a top-down strategy; $\mathrm{HR}=1.6,95 \% \mathrm{CI}=1.06$ 2.51) and discontinuation due to adverse events (vs. the discontinuation as part of a top-down strategy; $\mathrm{HR}=1.9,95 \% \mathrm{CI}=1.14-3.23$ ) were significantly associated with a higher risk of relapse.

The model was also evaluated considering only CD patients who had received the antiTNF agent owing to luminal disease (in comparison with UC), and the type of IBD was not associated with a higher risk of relapse $(\mathrm{HR}=1.03,95 \% \mathrm{CI}=0.79-1.34)$. Furthermore, we repeated the analysis after excluding patients with luminal CD to know whether the risk of relapse was higher among patients who received the anti-TNF drug owing to perianal CD in comparison with UC and observed that the risk was not increased $(\mathrm{HR}=1.04,95 \% \mathrm{CI}=0.77$ $1.41)$.

In a subanalysis, which included the 444 IBD patients who had undergone endoscopic evaluation before discontinuation, and that excluded those with CD in which perianal disease was the indication for anti-TNF therapy, the only factor associated with a higher risk of relapse was older age at discontinuation $(\mathrm{HR}=0.98,95 \% \mathrm{CI}=0.97-0.99)$. Thus, the presence of mucosal lesions in the endoscopy was not associated with a higher risk of relapse after 
discontinuation.

\section{Predictors of relapse in patients in deep remission}

In the univariate analysis performed in the group of $\mathrm{CD}$ patients with clinical remission and mucosal healing, the reasons for discontinuation (elective discontinuation, discontinuation due to adverse events, and discontinuation as part of a top-down strategy) was the only variable associated with the risk of relapse after withdrawal $(p<0.0001)$. In UC patients, disease extension (proctitis, left side colitis and extensive colitis) was the only variable statistically significant $(\mathrm{p}=0.002)$.

In the multivariate analysis, the only variable associated with a higher risk of relapse in CD patients was the discontinuation of anti-TNF treatment due to adverse events (vs. the discontinuation as part of a top-down strategy; $\mathrm{HR}=5.26,95 \% \mathrm{CI}=1.94-14.27$ ), while older age at anti-TNF discontinuation was associated with a lower risk of relapse $(\mathrm{HR}=0.97,95 \%$ $\mathrm{CI}=0.96-0.99)$. Gender, type of IBD, current smoking habit, prior surgery related to IBD, duration of anti-TNF treatment longer than 2 years, treatment with IMMs after anti-TNF discontinuation, and elective discontinuation (vs. discontinuation as a part of top-down strategy) were not associated with the risk of relapse. In UC patients, none of these variables were associated with the risk of relapse.

\section{Retreatment with anti-TNF drugs after relapse}

Of the $467(44 \%)$ patients who relapsed, $310(69 \%)$ were retreated with the same anti-TNF drug, $128(28 \%)$ received another drug, and $14(3 \%)$ were operated on (12 patients had CD and 2 patients had UC). Of the 310 retreated patients, 78\% received anti-TNF induction therapy. Also, $67 \%(95 \% \mathrm{CI}=61-72 \%)$ of these patients achieved clinical remission after 14 weeks of treatment. At the end of follow-up, $75 \%$ of patients $(95 \% \mathrm{CI}=70-80 \%)$ were in 
clinical remission and $13 \%(95 \% \mathrm{CI}=9-18 \%)$ had a partial response (Figure $4 \mathrm{a})$. Clinical remission was also achieved at the end of follow-up by $79 \%$ of patients $(95 \% \mathrm{CI}=72-85 \%)$ retreated with IFX and $69 \%$ of the patients retreated with ADA $(95 \% \mathrm{CI}=60-77 \%)$.

Eighty-six out of the 310 patients (28\%) restarted anti-TNF in monotherapy. From these patients, $53(62 \%)$ achieved clinical remission, and $16(19 \%)$ had a partial response. Patients who restarted anti-TNF in monotherapy achieved clinical remission less frequently than those who restarted anti-TNF combined with IMMs (68\% vs. $78 \% ; \mathrm{p}=0.08)$. The frequency of allergic reactions was similar among patients who restarted anti-TNF in monotherapy and those who restarted combo therapy (5.2\% vs. 5.8\%).

\section{Retreatment with anti-TNF drugs after relapse by type of IBD}

Of the $338 \mathrm{CD}$ patients who relapsed, $250(74 \%)$ were retreated with the same anti-TNF, $74(22 \%)$ were treated with another drug, and $14(4 \%)$ were operated on. In the case of UC patients, of the 129 patients who relapsed, 70 (54\%) were retreated with the same anti-TNF, 57 (44\%) received another drug, and $2(2 \%)$ were operated on. Response to retreatment by type of IBD is shown in figure $4 \mathrm{~b}$.

\section{Retreatment with anti-TNF drugs after relapse in patients in deep remission}

Of the 460 patients in deep remission who discontinued the anti-TNF, 177 relapsed. Of these, $125(71 \%)$ were retreated with the same anti-TNF, 49 (28\%) received another drug, and $3(1 \%)$ had surgery. At the end of follow-up, $78 \%(95 \% \mathrm{CI}=70-85 \%)$ of the patients were in clinical remission and $15 \%(95 \% \mathrm{CI}=8-20 \%)$ had a partial response. 


\section{Safety of the retreatment after relapse}

After retreatment, 34 of the total of patients who received an anti-TNF drug (11\%) experienced adverse events. Of these, 16 had infusion reactions, leading to the interruption of treatment in 6 cases. Nine patients presented adverse skin reactions but none of them had to discontinue treatment. Of the 6 patients who developed infections ( 2 pharyngitis, 1 varicella, 1 intra-abdominal abscess, 1 candidal intertrigo, and 1 miliary tuberculosis), 2 had to discontinue treatment because of the infection ( 1 of the patients with pharyngitis and the patient with miliary tuberculosis). Finally, 3 patients experienced other types of adverse events (dilated cardiomyopathy, memory loss, and leukopenia, respectively) and had to discontinue therapy. 


\section{DISCUSSION}

To our knowledge, the cohort analysed in the present study is the largest to date in IBD (1,055 patients, median follow-up of 2.4 years) in which the strategy of discontinuing antiTNF therapy after clinical remission has been evaluated. We found that the incidence of relapse was $18 \%$ per patient-year and that the cumulative incidence of relapse was $44 \%$ per patient-year. These findings confirm the relatively short duration of remission after discontinuation of anti-TNF therapy. Other studies have reported similar relapse rates ${ }^{10,16,24-27}$. The relapse rate 1 year after discontinuation was $24 \%$, which was slightly lower than in other $\operatorname{series}^{10,16,28}$, probably because almost all patients in whom endoscopic or radiologic activity had been investigated before stopping anti-TNF drugs had inactive disease. In fact, the relapse rate within 1 year of discontinuation in this group of patients was 14\%. Moreover, endoscopic activity was mild in most of the patients in whom activity was detected (12\%). Consequently, nearly $50 \%$ of the patients in our study stopped anti-TNF therapy after having achieved stable remission.

Experience with follow-up periods longer than 1 year after stopping anti-TNFs is very limited. A very recent meta-analysis of 27 studies reported an overall risk of relapse of $44 \%$ in IBD patients who discontinued anti-TNF agents after achieving clinical remission, whereas the reported risk of relapse in the long term ( $\geq 25$ months) was approximately $50 \%{ }^{14}$. Therefore, it seems that, over time, a relevant proportion of patients who stopped anti-TNF therapy will relapse. However, it is also true that a significant group of patients will maintain remission for a long period after stopping treatment. Accordingly, it is essential to identify the factors associated with risk of relapse.

We found that older age at discontinuation was a predictive factor of a lower risk of relapse, possibly because younger age has been identified as a predictive factor of poor 
outcome, since younger patients often have a more aggressive disease course ${ }^{28}$. Therefore, patients diagnosed with IBD at younger ages often begin anti-TNF treatment sooner than those diagnosed at older ages ${ }^{28}$. Indeed, in a recent study, Papamichael et al. followed $100 \mathrm{CD}$ patients who discontinued IFX upon achieving clinical remission for a median of 10 years and found a risk of relapse of $48 \%{ }^{29}$. Moreover, the authors found that age $\geq 25$ years at diagnosis of IBD was the only independent predictive factor for sustained clinical remission after discontinuation.

In the present study, ADA was associated with a higher relapse rate. For many years, IFX has been the only anti-TNF agent approved for IBD, thus explaining why ADA has been used as the second anti-TNF agent in many patients in whom IFX has previously failed or has lost efficacy. However, in the multivariate analysis, treatment with a previous anti-TNF agent was not associated with a higher risk of relapse after discontinuation. Finally, this finding could be a proxy for undetected variables that were not evaluated and that could be associated with a higher risk of relapse after discontinuation of anti-TNF therapy. Nevertheless, even though the higher risk of relapse after discontinuation of ADA was statistically significant, its magnitude was relatively low $(\mathrm{HR}=1.29,95 \% \mathrm{CI}=1.03-1.6)$ and, therefore, of uncertain clinical relevance.

The top-down strategy (i.e., early introduction of anti-TNF agents combined with thiopurines) is frequently used in patients with moderate to severe IBD and with predictive factors of poor outcome (e.g., younger age at diagnosis, early need for corticosteroids, fistulising phenotype, and perianal disease $)^{30}$. Patients who discontinue anti-TNF therapy after a top-down strategy are usually in stable remission (clinical, endoscopic, radiologic, and biochemical) before stopping therapy. Moreover, the rate of mucosal healing has been reported to be higher after a top-down strategy than with the conventional step-up approach; in addition, the top-down strategy could favour sustained remission ${ }^{4}$. These observations 
might explain why, in our study, patients who electively stopped anti-TNF agents and those who discontinued treatment owing to adverse events presented a significantly higher risk of relapse than those in whom anti-TNF drugs were stopped as part of a top-down strategy. Moreover, patients with a top-down approach were always naïve to IMMs. Consequently, IMMs alone might have been enough to maintain disease remission in some of these patients after stopping anti-TNF therapy. On the contrary, the patients in whom anti-TNF agents had been prescribed for a previous failure to IMMs probably have a higher risk of relapse after stopping anti-TNFs, even when IMMs are maintained. Although our findings seem logical for all the reasons set out above, the small sample size in the top-down group means that our results should be treated with caution.

Almost all the patients who underwent endoscopy before discontinuing anti-TNF drugs had inactive disease, although activity was mild in most of those with active disease. These findings could be explained by the fact that our study reflects routine clinical practice, in which physicians do not usually consider stopping anti-TNF therapy if moderate or severe endoscopic activity is detected, even though the patient is asymptomatic. A recent systematic review showed that the relapse rate was lower when discontinuation of anti-TNF treatment was based on both clinical and endoscopic remission as opposed to clinical remission alone $\mathrm{P}^{7}$ In this respect, a very recent meta-analysis showed that the incidence of relapse in CD patients, in whom the discontinuation of anti-TNF treatment was based exclusively in clinical remission, was $42 \%$. Similar findings were observed in UC patients. However, if the antiTNF was discontinued in patients in both clinical and endoscopic remission, the relapse rate was $26 \%{ }^{14}$. These findings suggest that mucosal healing is a major factor that should be evaluated when considering withdrawal of anti-TNF therapy. Nevertheless, other studies, including ours, were not able to demonstrate an association between mucosal healing and a lower relapse rate, either in CD and UC patients ${ }^{10,15,17,29,31}$. 
As for type of IBD, although some studies found a non-significant trend for longer remission in patients with $\mathrm{UC}^{11}$, our results showed no differences in the risk of relapse between $\mathrm{CD}$ and UC patients, even when we compared luminal and perianal involvement separately for both $\mathrm{CD}$ and $\mathrm{UC}$.

Approximately two-thirds of the patients in this cohort maintained IMMs after stopping anti-TNF drugs, and this was associated with a lower relapse rate. Not receiving concomitant medication with IMMs after stopping anti-TNF treatment has been associated with a higher risk of relapse ${ }^{8,32}$. IMMs enhance the efficacy of anti-TNF therapy, both in the short term and, probably, in the long term; accordingly, concomitant use of anti-TNF drugs with thiopurines, regardless of whether they had previously failed, is generally recommended in clinical practice $^{33}$. This beneficial effect of the IMMs might explain the lower risk of relapse in patients who maintained these drugs after stopping anti-TNF drugs. Finally, we did not find differences in the risk of relapse between patients who maintained thiopurines and those who maintained methotrexate, although the sample of the methotrexate group was too small to draw definitive conclusions.

When we performed a multivariate analysis separately for $\mathrm{CD}$, the factors associated with the risk of relapse were the same as for the overall IBD patients. Moreover, we found that colonic localization (vs. ileal) and stricturing behaviour (vs. inflammatory) were associated with a higher risk of relapse. However, these results should be taken with caution as they are part of a sensitivity analysis.

According to our results, retreatment with the same anti-TNF drug in IBD patients who relapsed after discontinuation was quite effective, inducing remission in $75 \%$ of patients. Even though similar findings have been reported in other studies, none has included as large a sample as the present study ${ }^{7,10,16,34,35}$. The high efficacy of re-initiation of anti-TNF drugs may merely reflect the fact that the patients treated with these drugs are a specific group that were 
previously identified as responders to anti-TNF therapy.

Patients who restarted anti-TNF in monotherapy achieved clinical remission less frequently than those who restarted anti-TNF in combination with IMMs $(62 \%$ vs. $78 \%$; $\mathrm{p}=0.08$ ). Although this difference was not statistically significant, there was a trend to a lower response in patients on anti-TNF in monotherapy. Moreover, in our study, the frequency of allergic reactions was similar among patients who restarted anti-TNF in monotherapy and those who restarted combo therapy. These findings are in agreement with data reported by other authors ${ }^{35}$.

Finally, we found that retreatment with the same anti-TNF drug was generally safe. However, 34 patients experienced adverse events which led to withdrawal in 11 patients. For this reason, the decision of stopping anti-TNF therapy should be individualized, and potential consequences (risks and benefits) should always be discussed with the patient.

Our study has several limitations. First, it is retrospective; therefore, the decision to stop anti-TNF agents was based on the subjective criteria of each physician. Moreover, the endoscopic scoring system was applied to individual patients reports, and the clinical activity scales were calculated reviewing medical records. Second, only half of the patients underwent endoscopic assessment at discontinuation. For this reason, and because most of the endoscopic lesions, if any, were mild, it was not possible to accurately determine whether mucosal healing was a predictor of a lower risk of relapse. However, considering that our study reflects daily clinical practice, the fact that a significant proportion of patients had undergone endoscopic evaluation was relevant. Furthermore, although laboratory parameters were collected from medical records, biochemical data were obtained only in a small number of patients.

One of the strengths of the present study is that - to our knowledge-it was based on the largest cohort of patients in whom anti-TNF therapy has been discontinued. In addition, data 
were collected from 78 Spanish hospitals, and the follow-up period was long, with a considerable number of patients followed for more than 5 years.

In conclusion, the results of this large multicentre study showed that approximately half of the patients who discontinued anti-TNF agents because of clinical remission relapse after discontinuation. We found that treatment with ADA, elective discontinuation of anti-TNF drugs, and discontinuation due to adverse events (vs. top-down strategy) were associated with a higher risk of relapse after discontinuation. On the contrary, the maintenance of treatment with IMMs and older age at discontinuation are associated with a lower risk of relapse. Based on these findings, discontinuation of anti-TNF therapy cannot be universally recommended in routine clinical practice. However, it seems that some patients can stop anti-TNF therapy safely and remain in remission for long periods. The decision whether to continue with antiTNF drugs should be taken on an individual basis and discussed with the patient. If the drug is discontinued and the patient with IBD relapses, the response to retreatment with the same anti-TNF is usually effective and safe. 


\section{REFERENCES}

1. Lichtenstein GR, Yan S, Bala M, Blank M, Sands BE. Infliximab maintenance treatment reduces hospitalizations, surgeries, and procedures in fistulizing Crohn's disease. Gastroenterology 2005; 128: 862-869.

2. Pineton de Chambrun G, Peyrin-Biroulet L, Lemann M, Colombel JF. Clinical implications of mucosal healing for the management of IBD. Nat Rev Gastroenterol Hepatol 2010; 7: 1529.

3. Schnitzler F, Fidder H, Ferrante M, Noman M, Arijs I, Van Assche G, et al. Mucosal healing predicts long-term outcome of maintenance therapy with infliximab in Crohn's disease. Inflamm Bowel Dis 2009; 15: 1295-1301.

4. Baert F, Moortgat L, Van Assche G, Caenepeel P, Vergauwe P, De Vos M, et al. Mucosal healing predicts sustained clinical remission in patients with early-stage Crohn's disease. Gastroenterology 2010; 138: 463-468; quiz e410-461.

5. Clarke K, Regueiro M. Stopping immunomodulators and biologics in inflammatory bowel disease patients in remission. Inflamm Bowel Dis 2012; 18: 174-179.

6. D'Haens GR, Panaccione R, Higgins PD, Vermeire S, Gassull M, Chowers Y, et al. The London Position Statement of the World Congress of Gastroenterology on Biological Therapy for IBD with the European Crohn's and Colitis Organization: when to start, when to stop, which drug to choose, and how to predict response? Am J Gastroenterol 2011; 106: 199-212; quiz 213.

7. Gisbert JP, Marin AC, Chaparro M. Systematic review: factors associated with relapse of inflammatory bowel disease after discontinuation of anti-TNF therapy. Aliment Pharmacol Ther 2015; 42: 391-405.

8. Waugh AW, Garg S, Matic K, Gramlich L, Wong C, Sadowski DC, et al. Maintenance of clinical benefit in Crohn's disease patients after discontinuation of infliximab: long-term 
follow-up of a single centre cohort. Aliment Pharmacol Ther 2010; 32: 1129-1134.

9. Molnar T, Farkas K, Miheller P, Nyari T, Szepes Z, Herszenyi L, et al. Is the efficacy of successful infliximab induction therapy maintained for one year lasting without retreatment in different behavior types of Crohn's disease? J Crohns Colitis 2008; 2: 322-326.

10. Molnar T, Lakatos PL, Farkas K, Nagy F, Szepes Z, Miheller P, et al. Predictors of relapse in patients with Crohn's disease in remission after 1 year of biological therapy. Aliment Pharmacol Ther 2013; 37: 225-233.

11. Steenholdt C, Molazahi A, Ainsworth MA, Brynskov J, Ostergaard Thomsen O, Seidelin JB. Outcome after discontinuation of infliximab in patients with inflammatory bowel disease in clinical remission: an observational Danish single center study. Scand J Gastroenterol 2012; 47: 518-527.

12. Farkas K, Lakatos PL, Nagy F, Szepes Z, Miheller P, Papp M, et al. Predictors of relapse in patients with ulcerative colitis in remission after one-year of infliximab therapy. Scand J Gastroenterol 2013.

13. Domenech E, Hinojosa J, Nos P, Garcia-Planella E, Cabre E, Bernal I, et al. Clinical evolution of luminal and perianal Crohn's disease after inducing remission with infliximab: how long should patients be treated? Aliment Pharmacol Ther 2005; 22: 1107-1113.

14. Gisbert JP, Marin AC, Chaparro M. The Risk of Relapse after Anti-TNF Discontinuation in Inflammatory Bowel Disease: Systematic Review and Meta-Analysis. Am J Gastroenterol 2016; 111: 632-647.

15. Molander P, Farkkila M, Salminen K, Kemppainen H, Blomster T, Koskela R, et al. Outcome after discontinuation of TNFalpha-blocking therapy in patients with inflammatory bowel disease in deep remission. Inflamm Bowel Dis 2014; 20: 1021-1028.

16. Louis E, Mary JY, Vernier-Massouille G, Grimaud JC, Bouhnik Y, Laharie D, et al. Maintenance of remission among patients with Crohn's disease on antimetabolite therapy after 
infliximab therapy is stopped. Gastroenterology 2012; 142: 63-70 e65; quiz e31.

17. Brooks AJ, Sebastian S, Cross SS, Robinson K, Warren L, Wright A, et al. Outcome of elective withdrawal of anti-tumour necrosis factor- $\alpha$ therapy in patients with Crohn's disease in established remission. J Crohns Colitis 2015; Epub ahead of print.

18. Harris PA, Taylor R, Thielke R, Payne J, Gonzalez N, Conde JG. Research electronic data capture (REDCap)--a metadata-driven methodology and workflow process for providing translational research informatics support. J Biomed Inform 2009; 42: 377-381.

19. Harvey RF, Bradshaw JM. A simple index of Crohn's-disease activity. Lancet 1980; 1: 514.

20. D'Haens G, Feagan B, Colombel JF, Sandborn WJ, Reinisch W, Rutgeerts P, et al. Challenges to the design, execution, and analysis of randomized controlled trials for inflammatory bowel disease. Gastroenterology 2012; 143: 1461-1469.

21. Present DH, Rutgeerts P, Targan S, Hanauer SB, Mayer L, van Hogezand RA, et al. Infliximab for the treatment of fistulas in patients with Crohn's disease. N Engl J Med 1999; 340: 1398-1405.

22. Rutgeerts P, Geboes K, Vantrappen G, Beyls J, Kerremans R, Hiele M. Predictability of the postoperative course of Crohn's disease. Gastroenterology 1990; 99: 956-963.

23. Schroeder KW, Tremaine WJ, Ilstrup DM. Coated oral 5-aminosalicylic acid therapy for mildly to moderately active ulcerative colitis. A randomized study. N Engl J Med 1987; 317: $1625-1629$.

24. Chauvin A, Le Thuaut A, Belhassan M, Le Baleur Y, Mesli F, Bastuji-Garin S, et al. Infliximab as a bridge to remission maintained by antimetabolite therapy in Crohn's disease: A retrospective study. Dig Liver Dis 2014; 46: 695-700.

25. Armuzzi A, Marzo M, Felice C, De Vincentis F, Andrisani G, Moccio G ea. Long-term scheduled therapy with infliximab in inflammatory bowel disease: a single-centre 
observational study. Gastroenterology 2010; 238 (suppl.1): S-691.

26. Luppino I, Spagnuolo R, Marasco R, Cosco C, Ruggiero G, Cosco V, et al. Withdrawal of infliximab (IFX) after achieving remission: outcome in a cohort of inflammatory bowel disease (IBD) patients. Dig Liver Dis. [Conference abstract: Abstracts of the 19th National Congress of Digestive Diseases]. 2013; 45S: S100-S101.

27. Nuti F, Conte F, Cavallari N, Civitelli F, Aloi M, Alessandri C, et al. Long term efficacy of infliximab in inflammatory bowel disease at a single tertiary center. Dig Liver Dis. [Congress comunication: 17th National Congress SIGENP]. 2010; 42(SUPPL. 5): S326-S327. 28. Gearry RB, Kamm MA, Hart AL, Bassett P, Gabe SM, Nightingale JM. Predictors for developing intestinal failure in patients with Crohn's disease. J Gastroenterol Hepatol 2013; 28: 801-807.

29. Papamichael K, Vande Casteele N, Gils A, Tops S, Hauenstein S, Singh S, et al. Longterm outcome of patients with Crohn's disease who discontinued infliximab therapy upon clinical remission. Clin Gastroenterol Hepatol 2015; 13: 1103-1110.

30. D'Haens G, Baert F, van Assche G, Caenepeel P, Vergauwe P, Tuynman H, et al. Early combined immunosuppression or conventional management in patients with newly diagnosed Crohn's disease: an open randomised trial. Lancet 2008; 371: 660-667.

31. Farkas K, Lakatos PL, Szucs M, Pallagi-Kunstar E, Balint A, Nagy F, et al. Frequency and prognostic role of mucosal healing in patients with Crohn's disease and ulcerative colitis after one-year of biological therapy. World J Gastroenterol 2014; 20: 2995-3001.

32. Bortlík M, Duricova D, Lukas M, Malíčková K, Machkova N, Hrdlicka L, et al. In. 20th United European Gastroenterology Week 2012: P0870.

33. Cabriada JL, Vera I, Domenech E, Barreiro-de Acosta M, Esteve M, Gisbert JP, et al. [Recommendations of the Spanish Working Group on Crohn's disease and ulcerative colitis on the use of anti-tumor necrosis factor drugs in inflammatory bowel disease]. Gastroenterol 
Hepatol 2013; 36: 127-146.

34. Eshuis EJ, Peters CP, van Bodegraven AA, Bartelsman JF, Bemelman W, Fockens P, et al. Ten years of infliximab for Crohn's disease: outcome in 469 patients from 2 tertiary referral centers. Inflamm Bowel Dis 2013; 19: 1622-1630.

35. Domenech E, Zabana Y, Manosa M, Garcia-Planella E, Cabre E, Gassull MA. Infliximab reintroduction is not associated to a higher rate of immune-related adverse effects in patients with inflammatory bowel disease initially treated with a three-infusion induction regimen. $\mathrm{J}$ Clin Gastroenterol 2010; 44: 34-37. 
Guarantor of the article: J.P. Gisbert, MD, $\mathrm{PhD}$.

Specific author contributions: M.J. Casanova, M. Chaparro, and J.P. Gisbert conceived and designed this study. All the authors participated in the collection of data of patients. M.J. Casanova, M. Chaparro, and J.P. Gisbert analyzed and interpreted the results and wrote the manuscript. All the authors critically reviewed the manuscript, and have read and approved the final version of the manuscript.

Financial support: none

Potential competing interests: MJ Casanova: has received research funding from Abbott. Javier P. Gisbert and María Chaparro have served as speakers, consultants, and advisory members for and have received research funding from MSD and Abbvie. E. Domenech has served as a consultant and an advisory board for MSD and Abbott, and has received research funding from MSD and Abbott; F. Gomollón has received fees for conferences and received grants for assistance to scientific meetings from Abbott and MSD; X. Calvet has received grants for research, fees for advisory boards, and lectures from Abott and MSD; S. GarcíaLópez has received grants for assistance to scientific meetings from Abbott, MSD. He has also received consultancy fees from Abbott and MSD; C. Taxonera has served as speaker, consultant, and advisory for Abbott, MSD, and Shire; M. Barreiro-de Acosta has served as a consultant and an advisory board member for MSD and Abbott; M. Esteve has served as an advisory board for Abbott and MSD. All the other authors: none. 
Table 1. Baseline characteristics of the patients.

\begin{tabular}{|c|c|c|c|}
\hline Variables & Total & CD & $\mathbf{U C}$ \\
\hline Type of disease, $\mathrm{n}(\%)$ & $1.055(100)$ & $731(69)$ & $324(31)$ \\
\hline Male, n (\%) & $526(49.9)$ & $349(47.7)$ & $177(54.6)$ \\
\hline Mean age at diagnosis, years (range) & $30(6-76)$ & $29(6-76)$ & $35(9-71)$ \\
\hline Mean age at discontinuation, years (range) & $38(13-82)$ & $37(13-82)$ & $42(16-79)$ \\
\hline Mean age, years (range) & $42(17-85)$ & $41(17-85)$ & $46(17-82)$ \\
\hline Extra-intestinal manifestations, $\mathrm{n}(\%)$ & $287(27)$ & $217(29.9)$ & $70(21.7)$ \\
\hline Current smokers, $\mathrm{n}(\%)$ & $239(24)$ & $203(29)$ & $36(11.4)$ \\
\hline History of abdominal surgery, n (\%) & $248(24)$ & $238(32.8)$ & $10(3.2)$ \\
\hline $\begin{array}{l}\text { Type of anti-TNF therapy, } n(\%) \\
\text {-IFX } \\
\text {-ADA }\end{array}$ & $\begin{array}{l}781(74) \\
274(26) \\
\end{array}$ & $\begin{array}{l}485(66.3) \\
246(33.7)\end{array}$ & $\begin{array}{c}296(91.4) \\
28(8.6) \\
\end{array}$ \\
\hline $\begin{array}{l}\text { Treatment following anti-TNF withdrawal, n (\%) } \\
\text {-Thiopurines } \\
\text {-MTX } \\
\text {-5-ASA } \\
\text {-None }\end{array}$ & $\begin{aligned} 689(65) \\
29(3) \\
149(14) \\
188(18)\end{aligned}$ & $\begin{array}{l}480(65.7) \\
22(3) \\
65(8.9) \\
164(22.4)\end{array}$ & $\begin{array}{l}209(64.5) \\
7(2.2) \\
84(25.9) \\
24(7.4)\end{array}$ \\
\hline $\begin{array}{l}\text { Endoscopy at the moment of anti-TNF withdrawal, n (\%) } \\
\text {-Endoscopic activity } \\
\text {-Mild activity } \\
\text {-Moderate activity } \\
\text {-Severe activity } \\
\text {-Unknown grade of activity }\end{array}$ & $\begin{array}{l}474(45) \\
55(12) \\
38(69) \\
4(7) \\
2(4) \\
11(20)\end{array}$ & $\begin{array}{l}279(58.9) \\
10(3.6) \\
2(0.7) \\
1(2.5) \\
7(2.5) \\
\end{array}$ & $\begin{array}{c}195(41.1) \\
28(14.4) \\
2(1) \\
1(2.1) \\
4(2.1) \\
\end{array}$ \\
\hline $\begin{array}{l}\text { Montreal location at CD diagnosis, } \mathrm{n}(\%) \\
\text {-L1 (ileal) } \\
\text {-L2 (colonic) } \\
\text {-L3 (ileocolonic) } \\
\text {-L4 (upper gastrointestinal tract) }\end{array}$ & $\begin{array}{c}200(27.4) \\
159(21.7) \\
371(50.7) \\
1(0.2) \\
\end{array}$ & & \\
\hline $\begin{array}{l}\text { Montreal behaviour at CD diagnosis, } \mathrm{n}(\%) \\
\text {-B1 (inflammatory) } \\
\text {-B2 (stricturing) } \\
\text {-B3 (penetrating) } \\
\text {-Unknown }\end{array}$ & $\begin{array}{l}432(59) \\
126(17) \\
161(22) \\
12(2)\end{array}$ & & \\
\hline Perianal disease, $\mathrm{n}(\%)$ & $277(38)$ & & \\
\hline $\begin{array}{l}\text { UC extension, } \mathrm{n}(\%) \\
\text {-Proctitis } \\
\text {-Left side colitis } \\
\text {-Extensive colitis }\end{array}$ & $\begin{array}{c}19(6) \\
108(33) \\
197(61)\end{array}$ & & \\
\hline $\begin{array}{l}\text { CD with MRI at the moment of anti-TNF withdrawal, } n \\
\text {-Radiological activity, } n(\%)\end{array}$ & $\begin{array}{c}88 \\
9(10) \\
\end{array}$ & & \\
\hline
\end{tabular}

CD: Crohn's disease; UC: ulcerative colitis; IMMs: immunomodulators; MTX: methotrexate; 5-ASA: 5aminosalicylates; IFX: infliximab; ADA: adalimumab; MRI: magnetic resonance imaging. 
Table 2. Baseline characteristics of the patients in deep remission at the moment of anti-TNF discontinuation.

\begin{tabular}{|c|c|c|c|}
\hline Variables & Total & CD & $\mathbf{U C}$ \\
\hline Type of disease, $\mathrm{n}(\%)$ & $460(100)$ & $300(65.2)$ & $160(34.8)$ \\
\hline Male, n (\%) & $235(51.1)$ & $143(47.7)$ & $92(58)$ \\
\hline Mean age at diagnosis, years (range) & $31(7-70)$ & $29(7-69)$ & $34(9-70)$ \\
\hline Mean age at discontinuation, years (range) & $38(15-80)$ & $36(15-80)$ & $42(16-74)$ \\
\hline Mean age, years (range) & $42(17-82)$ & $40(17-82)$ & $45(18-75)$ \\
\hline Extra-intestinal manifestations, n (\%) & $103(22.5)$ & $70(23.5)$ & $33(20.6)$ \\
\hline Current smokers, n (\%) & $87(19.3)$ & $69(23.6)$ & $18(11.4)$ \\
\hline History of abdominal surgery, $\mathrm{n}(\%)$ & $104(23)$ & $101(66)$ & $3(1.8)$ \\
\hline $\begin{array}{l}\text { Type of anti-TNF therapy, } \mathrm{n}(\%) \\
\text {-IFX } \\
\text {-ADA }\end{array}$ & $\begin{array}{l}335(72.8) \\
125(27.2)\end{array}$ & $\begin{array}{l}189(63) \\
111(37)\end{array}$ & $\begin{array}{c}146(91.3) \\
14(8.8)\end{array}$ \\
\hline Anti-TNF longer than 2 years before withdrawal & $193(45.8)$ & $127(48)$ & $66(43)$ \\
\hline $\begin{array}{l}\text { Reasons to discontinue anti-TNF therapy } \\
\text {-Elective decision } \\
\text {-Top down strategy } \\
\text {-Adverse events }\end{array}$ & $\begin{array}{l}400(87) \\
24(5.2) \\
36(7.8) \\
\end{array}$ & $\begin{array}{l}255(85) \\
20(6.7) \\
25(8.3) \\
\end{array}$ & $\begin{array}{c}145(90.6) \\
4(2.5) \\
11(6.9) \\
\end{array}$ \\
\hline $\begin{array}{l}\text { Treatment following anti-TNF withdrawal, n (\%) } \\
\text {-Thiopurines } \\
\text {-MTX } \\
\text {-5-ASA } \\
\text {-None }\end{array}$ & $\begin{array}{l}345(75) \\
9(2) \\
66(14.3) \\
40(8.7)\end{array}$ & $\begin{array}{l}232(77.3) \\
6(2) \\
23(7.7) \\
39(13)\end{array}$ & $\begin{aligned} 113 & (70.6) \\
3 & (1.9) \\
43 & (26.9) \\
1 & (0.6)\end{aligned}$ \\
\hline $\begin{array}{l}\text { Montreal location at CD diagnosis, } \mathrm{n}(\%) \\
\text {-L1 (ileal) } \\
\text {-L2 (colonic) } \\
\text {-L3 (ileocolonic) }\end{array}$ & $\begin{array}{c}74(24.7) \\
78(26) \\
148(49.3)\end{array}$ & & \\
\hline $\begin{array}{l}\text { Montreal behaviour at CD diagnosis, } \mathrm{n}(\%) \\
\text {-B1 (inflammatory) } \\
\text {-B2 (stricturing) } \\
\text {-B3 (penetrating) } \\
\text {-Unknown }\end{array}$ & $\begin{array}{l}176(58.7) \\
55(18.3) \\
66(22) \\
3(1) \\
\end{array}$ & & \\
\hline Perianal disease, $\mathrm{n}(\%)$ & $113(37.6)$ & & \\
\hline $\begin{array}{l}\text { UC extension, n }(\%) \\
\text {-Proctitis } \\
\text {-Left side colitis } \\
\text {-Extensive colitis }\end{array}$ & $\begin{array}{l}7(4.4) \\
57(5.6) \\
96(60)\end{array}$ & & \\
\hline
\end{tabular}

CD: Crohn's disease; UC: ulcerative colitis; IMMs: immunomodulators; MTX: methotrexate; 5-ASA: 5aminosalicylates; IFX: infliximab; ADA: adalimumab; MRI: magnetic resonance imaging. 
Table 3. Factors associated with the risk of relapse after discontinuation of anti-TNF therapy in the multivariate analysis.

\begin{tabular}{|c|c|c|c|}
\hline Factors & HR & 95\% CI & $P$-value \\
\hline $\begin{array}{c}\text { Maintenance of IMMs after } \\
\text { discontinuation }\end{array}$ & 0.70 & $0.57-0.88$ & 0.002 \\
\hline Older age at discontinuation & 0.99 & $0.98-0.99$ & $<0.0001$ \\
\hline $\begin{array}{c}\text { Treatment with ADA (vs. IFX) } \\
\begin{array}{c}\text { Elective discontinuation (vs. } \\
\text { discontinuation for top-down } \\
\text { strategy) }\end{array}\end{array} \quad 1.29$ & $1.03-1.60$ & 0.027 \\
\hline $\begin{array}{c}\text { Discontinuation due to adverse } \\
\text { events (vs. discontinuation as part } \\
\text { of a top-down strategy) }\end{array}$ & 1.95 & $1.19-2.79$ & 0.006 \\
\hline
\end{tabular}

HR: hazard ratio; IMMs: immunomodulators; ADA: adalimumab; IFX: infliximab; CI: confidence interval. 
Table 4. Factors associated with the risk of relapse after discontinuation of anti-TNF therapy in the multivariate analysis in CD.

\begin{tabular}{|c|c|c|c|}
\hline Factors & HR & $95 \% \mathrm{CI}$ & $P$-value \\
\hline $\begin{array}{l}\text { Maintenance of IMMs after } \\
\text { discontinuation* }\end{array}$ & 0.67 & $0.51-0.87$ & 0.003 \\
\hline Older age at discontinuation* & 0.98 & $0.97-0.99$ & 0.001 \\
\hline Treatment with ADA (vs. IFX)* & 1.29 & $1.01-1.66$ & 0.04 \\
\hline $\begin{array}{l}\text { Elective discontinuation (vs. } \\
\text { discontinuation for top-down } \\
\text { strategy)* }\end{array}$ & 1.90 & $1.07-3.37$ & 0.03 \\
\hline $\begin{array}{l}\text { Discontinuation due to adverse } \\
\text { events (vs. discontinuation as part of } \\
\text { a top-down strategy)* }\end{array}$ & 2.33 & $1.27-4.29$ & 0.006 \\
\hline Colonic localization (vs. ileal)* & 1.51 & $1.13-2.02$ & 0.005 \\
\hline $\begin{array}{l}\text { Stricturing behaviour (vs. } \\
\text { inflammatory)* }\end{array}$ & 1.50 & $1.09-2.05$ & 0.01 \\
\hline
\end{tabular}

HR: hazard ratio; IMMs: immunomodulators; ADA: adalimumab; IFX: infliximab; CI: confidence interval.

(*) adjusted by duration of anti-TNF therapy 


\section{Figure legends:}

Figure 1a. Kaplan-Meier curve showing the probability of survival without relapse after discontinuation of anti-TNF therapy for the whole study cohort.

Figure 1b. Kaplan-Meier curve showing the probability of survival without relapse after discontinuation of anti-TNF therapy for Crohn's disease patients.

Figure 1c. Kaplan-Meier curve showing the probability of survival without relapse after discontinuation of anti-TNF therapy for ulcerative colitis patients.

Figure 2. Kaplan-Meier curves showing the risk of relapse in patients treated vs. not treated with immunomodulators after discontinuation of anti-TNF therapy.

Figure 3. Kaplan-Meier curves showing the risk of relapse depending on the reason for discontinuation of anti-TNF therapy.

Figure 4a. Response to the retreatment with the same anti-TNF in patients who relapsed after discontinuing anti-TNF therapy.

Figure 4b. Response to the retreatment with the same anti-TNF at the end of follow-up in Crohn's disease and ulcerative colitis patients who relapsed after discontinuing anti-TNF therapy. 


\section{EVOLUTION AFTER ANTI-TNF DISCONTINUATION IN PATIENTS WITH INFLAMMATORY BOWEL DISEASE: A MULTICENTER LONG-TERM FOLLOW-UP STUDY}

SHORT TITLE: Evolution after anti-TNF discontinuation in IBD patients

\section{AUTHORS}

MJ. Casanova ${ }^{1}$, M. Chaparro ${ }^{1}$, V. García-Sánchez ${ }^{2}$, O. Nantes ${ }^{3}$, E. Leo ${ }^{4}$, M. Rojas-Feria ${ }^{5}$, A. Jauregui-Amezaga ${ }^{6}$, S. García-López ${ }^{7}$, JM. Huguet ${ }^{8}$, F. Arguelles-Arias ${ }^{9}$, M. Aicart ${ }^{10}$, I. Marín-Jiménez $^{11}$, M. Gómez-García ${ }^{12}, \mathrm{~F}$. Muñoz ${ }^{13}$, M. Esteve ${ }^{14}$, L. Bujanda $^{15}$, X. Cortés ${ }^{16}$, J.

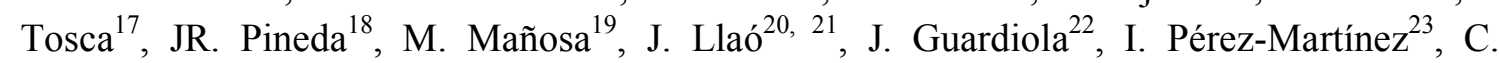
Muñoz $^{24}$, Y. González-Lama ${ }^{25}$, J. Hinojosa ${ }^{26}$, JM. Vázquez ${ }^{27}$, MP. Martinez-Montiel $^{28}$, GE. Rodríguez $^{29}$, R. Pajares ${ }^{30}$, MF. García-Sepulcre ${ }^{31}$, A. Hernández-Martínez ${ }^{32}$, JL. PérezCalle $^{33}$, B. Beltrán ${ }^{34}$ D. Busquets ${ }^{35}$, L. Ramos ${ }^{36}$, F. Bermejo ${ }^{37}$, J. Barrio ${ }^{38}$, M. Barreiro-de Acosta $^{39}$, O. Roncedo ${ }^{40}$, X. Calvet ${ }^{41}$, D. Hervías ${ }^{42}$, F. Gomollón ${ }^{43}$, M. DomínguezAntonaya $^{44}$, G. Alcaín ${ }^{45}$, B. Sicilia ${ }^{46}$, C. Dueñas ${ }^{47}$, A. Gutiérrez ${ }^{48}$, R. Lorente-Poyatos ${ }^{49}$, M. Domínguez $^{50}$, S. Khorrami ${ }^{51}$, C. Muñoz ${ }^{52}$, C. Taxonera ${ }^{53}$, A. Rodríguez-Pérez ${ }^{54}$, A. Ponferrada $^{55}$, M. Van Domselaar ${ }^{56}$, ML. Arias-Rivera ${ }^{57}$, O. Merino ${ }^{58}$, E. Castro ${ }^{59}$, JM. Marrero $^{60}$, M. Martín-Arranz ${ }^{61}$, B. Botella ${ }^{62}$, L. Fernández-Salazar ${ }^{63}$, D. Monfort ${ }^{64}$, V. Opio ${ }^{65}$, A. García-Herola ${ }^{66}$, M. Menacho ${ }^{67}$, P. Ramírez-de la Piscina ${ }^{68}$, D. Ceballos ${ }^{69}$, P. Almela ${ }^{70}$, M. Navarro-Llavat $^{71}$, V. Robles-Alonso ${ }^{72}$, AB. Vega-López ${ }^{73}$, I. Moraleja ${ }^{74}$, MT. Novella ${ }^{75}$, C. Castaño-Milla $^{76}$, A. Sánchez-Torres ${ }^{77}$, JM. Benítez ${ }^{2}$, C. Rodríguez ${ }^{3}$, L. Castro ${ }^{9}$, E. Garrido ${ }^{10}$, E. Domènech ${ }^{19}$, E. García-Planella ${ }^{20}$ and JP. Gisbert ${ }^{1}$

Gastroenterology Departments from: ${ }^{1}$ Hospital Universitario de La Princesa, Instituto de Investigación Sanitaria Princesa (IIS-IP) and Centro de Investigación Biomédica en Red de Enfermedades Hepáticas y Digestivas (CIBEREHD), Madrid; ${ }^{2}$ Hospital Universitario Reina Sofía, Córdoba; ${ }^{3}$ Complejo Hospitalario de Navarra and Instituto de Investigación Sanitaria de Navarra (IdiSNA), Pamplona; ${ }^{4}$ Hospital Universitario Virgen del Rocío, Sevilla; ${ }^{5}$ Hospital Universitario de Valme, and CIBEREHD, Sevilla; ${ }^{6}$ Hospital Clínic i Provincial, and CIBEREHD, Barcelona; ${ }^{7}$ Hospital Universitario Miguel Servet, Zaragoza; ${ }^{8}$ Consorcio Hospital General Universitario de Valencia, Valencia; ${ }^{9}$ Hospital Universitario Virgen Macarena, Sevilla; ${ }^{10}$ Hospital Universitario Ramón y Cajal, Madrid; ${ }^{11}$ Hospital Universitario Gregorio Marañón and Instituto de Investigación Sanitaria Gregorio Marañón (IiSGM), Madrid; ${ }^{12}$ Hospital Universitario Virgen de las Nieves, Granada; ${ }^{13}$ Complejo Universitario de León, León; ${ }^{14}$ Hospital Universitario Mutua Terrassa, Terrassa, and CIBEREHD; ${ }^{15}$ Hospital Universitario de Donostia, Instituto Biodonostia, Universidad del País Vasco UPV/EHU, and CIBEREHD, Donostia; ${ }^{16}$ Hospital de Sagunto, Valencia; ${ }^{17}$ Hospital Clínico Valencia, Valencia; ${ }^{18}$ Complejo Hospitalario Universitario de Vigo, Vigo, ${ }^{19}$ Hospital Universitari Germans Trias i Pujol, Badalona, and CIBEREHD; ${ }^{20}$ Hospital de la Santa Creu I Sant Pau, Barcelona; ${ }^{21}$ Hospital Sant Joan de Deu, Manresa; ${ }^{22}$ Hospital Universitario de Bellvitge, Barcelona; ${ }^{23}$ Hospital Universitario Central de Asturias, Oviedo; ${ }^{24}$ Hospital de Basurto, Bilbao; ${ }^{25}$ Hospital Universitario Puerta de Hierro, Madrid; ${ }^{26}$ Hospital de Manises, Valencia; ${ }^{27}$ Hospital Juan Ramón Jiménez, Huelva; ${ }^{28}$ Hospital Universitario Doce de Octubre, Madrid; 
${ }^{29}$ Hospital Universitario Nuestra Señora de la Candelaria, Santa Cruz de Tenerife; ${ }^{30}$ Hospital Universitario Infanta Sofía, Madrid; ${ }^{31}$ Hospital General Universitario de Elche, Alicante; ${ }^{32}$ Hospital Torrecárdenas, Almería; ${ }^{33}$ Hospital Universitario Fundación de Alcorcón, Madrid; ${ }^{34}$ Hospital Universitario La Fe, Valencia, and CIBEREHD; ${ }^{35}$ Hospital Universitari de Girona Dr. Josep Trueta, Girona; ${ }^{36}$ Hospital Universitario de Canarias, La Laguna; ${ }^{37}$ Hospital Universitario de Fuenlabrada, Madrid; ${ }^{38}$ Hospital Universitario Río Hortega, Valladolid; ${ }^{39}$ Hospital Clínico Universitario de Santiago de Compostela, Santiago de Compostela; ${ }^{40}$ Hospital Villafranca de los Caballeros, Toledo; ${ }^{41}$ Hospital de Sabadell, Corporació Sanitària Universitària Parc Taulí, Sabadell, and CIBEREHD; ${ }^{42}$ Hospital Virgen de Altagracia, Ciudad Real; ${ }^{43}$ Hospital Clínico Lozano Blesa, Zaragoza, Instituto de Investigación Sanitaria Aragón (IIS Aragón), and CIBEREHD; ${ }^{44}$ Hospital Universitario de Móstoles; ${ }^{45}$ Hospital Virgen de la Victoria, Málaga; ${ }^{46}$ Hospital Universitario de Burgos, Burgos; ${ }^{47}$ Hospital Universitario San Pedro Alcántara, Cáceres; ${ }^{48}$ Hospital General Universitario de Alicante, Alicante, and CIBEREHD; ${ }^{49}$ Hospital General de Ciudad Real, Ciudad Real; ${ }^{50}$ Hospital General San Jorge, Huesca; ${ }^{51}$ Hospital Universitario Son Espases, Palma de Mallorca; ${ }^{52}$ Hospital Virgen de la Salud, Toledo; ${ }^{53}$ Hospital Universitario Clínico San Carlos and Instituto de Investigación del Hospital Clínico San Carlos (IdISSC), Madrid; ${ }^{54}$ Hospital Universitario De Salamanca, Salamanca; ${ }^{55}$ Hospital Universitario Infanta Leonor, Madrid; ${ }^{56}$ Hospital de Torrejón de Ardoz, Madrid; ${ }^{57}$ Hospital Universitario Severo Ochoa, Madrid; ${ }^{58}$ Hospital Universitario Cruces, Barakaldo; ${ }^{59}$ Hospital Lucus Augusti, Lugo; ${ }^{60}$ Hospital Universitario Insular de Gran Canaria, Las Palmas de Gran Canaria; ${ }^{61}$ Hospital Universitario La Paz, Madrid; ${ }^{62}$ Hospital Universitario Infanta Cristina, Madrid; ${ }^{63}$ Hospital Clínico Universitario de Valladolid, Valladolid; ${ }^{64}$ Consorci Sanitari Terrassa, Terrassa; ${ }^{65}$ Hospital Universitario de Getafe, Madrid; ${ }^{66}$ Hospital Marina Baixa, Alicante; ${ }^{67}$ Hospital Joan XXIII, Tarragona; ${ }^{68}$ Hospital Universitario de Álava, Vitoria; ${ }^{69}$ Hospital Universitario Dr. Negrín, Las Palmas de Gran Canaria; ${ }^{70}$ Hospital General Universitario de Castellón, Castellón; ${ }^{71}$ Hospital de Sant Joan Despí Moisès Broggi, Sant Joan Despí; ${ }^{72}$ Hospital Universitari Vall d'Hebron, Barcelona; ${ }^{73}$ Hospital de Viladecans, Barcelona; ${ }^{74}$ Hospital de Galdakao-Usansolo, Galdakao; ${ }^{75}$ Hospital Can Misses, Eivissa; ${ }^{76}$ Hospital Universitario Rey Juan Carlos, Madrid; ${ }^{77}$ Hospital Virgen de la Arrixaca, Murcia, Spain.

\section{ABBREVIATIONS}

Anti-tumor necrosis factor- $\alpha$ (anti-TNF), confidence interval (CI), Crohn's disease (CD), inflammatory bowel disease (IBD), ulcerative colitis (UC), immunomodulators (IMMs), 5aminosalicylates (5-ASA), magnetic resonance imaging (MRI), hazard ratio (HR).

\section{KEY WORDS}

Inflammatory bowel disease, Crohn's disease, ulcerative colitis, anti-TNF, infliximab, adalimumab, discontinuation, withdrawal.

\section{CORRESPONDENCE}

Javier P. Gisbert, M.D. Gastroenterology Unit. La Princesa Hospital. Diego de León, 62. 28006 Madrid, Spain. Tel.: 34-913093911; Fax: 34-914022299. E-mail:

javier.p.gisbert@gmail.com 


\section{STUDY HIGHLIGHTS}

Current Knowledge

- The risk of relapse after anti-TNF withdrawal are not well known.

- The variables that impact clinical course after withdrawal are not well known.

- The efficacy and safety of retreatment with the same anti-TNF drug in patients who relapse seem to be high.

- Currently available data are insufficient to make recommendations on when anti-TNF therapy can be stopped.

What is new here

- Approximately half of the patients who discontinued anti-TNF agents because of clinical remission relapse after discontinuation.

- Treatment with ADA, elective discontinuation of anti-TNF drugs, and discontinuation due to adverse events increase the risk of relapse.

- Treatment with IMMs and older age at discontinuation are associated with a lower risk of relapse.

- Discontinuation of anti-TNF therapy cannot be universally recommended. However, some patients can stop anti-TNF therapy safely and remain in remission for long periods. 


\section{SUMMARY}

AIMS: To assess the risk of relapse after discontinuation of anti-TNF drugs in patients with inflammatory bowel disease, to identify the factors associated with relapse, and to evaluate the response to and safety of retreatment with the same anti-TNF after relapsing.

METHODS: Retrospective, observational, multicentre study. Patients with Crohn's disease or ulcerative colitis who had been treated with anti-TNFs and in whom these drugs were discontinued after clinical remission was achieved were included.

RESULTS: 1,055 patients were included. The cumulative incidence of relapse was 44\%: $24 \%$ at 1 year, $38 \%$ at 2 years, $46 \%$ at 3 years, and $56 \%$ at 5 years after anti-TNF discontinuation. The incidence rate of relapse was $18 \%$ per patient-year. The variables associated with a higher risk of relapse were treatment with adalimumab vs. infliximab $(\mathrm{HR}=1.29 ; 95 \% \mathrm{CI}=1.03-1.60)$ and elective discontinuation of anti-TNFs $(\mathrm{HR}=1.82 ; 95 \% \mathrm{CI}=1.19-2.79) \quad$ or discontinuation due to adverse events $(\mathrm{HR}=1.95 ; 95 \% \mathrm{CI}=1.22-3.12)$ vs. a top-down strategy. Treatment with immunomodulators after discontinuation $(\mathrm{HR}=0.70 ; 95 \% \mathrm{CI}=0.57-0.88)$ and age $(\mathrm{HR}=0.99 ; 95 \% \mathrm{CI}=0.98-0.99)$ were associated with a lower risk of relapse. Retreatment of relapse with the same anti-TNF was effective (88\% responded) and safe.

CONCLUSIONS: The incidence rate of relapse after anti-TNF discontinuation in patients with inflammatory bowel disease who were in remission was $18 \%$ per patient-year. Treatment with adalimumab, the elective discontinuation of anti-TNFs, or discontinuation of anti-TNFs due to adverse events (vs. top-down strategy) increased the risk of relapse. Older age and maintenance treatment with immunomodulators were associated with a lower risk of relapse. Retreatment with the same anti-TNF drug was effective and safe. 


\section{INTRODUCTION}

Anti-tumour necrosis factor- $\alpha$ (anti-TNF) drugs are effective in inducing and maintaining remission in patients with inflammatory bowel diseases (IBD), namely, Crohn's disease (CD) and ulcerative colitis (UC) ${ }^{1}$. This effectiveness is associated with mucosal healing, improved quality of life, fewer hospitalizations, and reduced need for surgical procedures ${ }^{1-4}$.

Discontinuation of anti-TNF treatment can be considered once remission has been achieved. The decision to discontinue anti-TNF drugs in patients in remission depends on several factors, such as the cost of the medications, the potential but serious adverse effects, and the outcome following elective withdrawal ${ }^{5}$. Once it has been decided that the drug is to be withdrawn, the optimal time for doing so must be established ${ }^{6}$.

Studies evaluating this strategy are mostly single-cohort designs, and most of them include a small number of patients and have a short follow-up period ${ }^{7}$. Therefore, the risk of relapse after withdrawal of anti-TNF medication and the variables that impact clinical course after withdrawal are not well known. Data from small observational studies of patients who discontinued anti-TNF therapy after having achieved clinical remission show that the range of relapse rates is wide ${ }^{8-14}$.

The retreatment with the same anti-TNF drug in patients who relapse after the initial withdrawal have been reported to be apparently successful and safe $\mathrm{e}^{12,15-17}$, and these factors are essential before deciding whether to discontinue anti-TNF therapy. However, there are many concerns relating to discontinuation of anti-TNF therapy in IBD patients that include not only the risk of relapse, but the possible loss of efficacy when the drug is restarted, the risk of infusion reactions and other adverse events at retreatment, and, finally, the possibility of losing therapeutic options. Therefore, currently available data are insufficient to make recommendations on when, if ever, anti-TNF therapy can be stopped in patients with IBD. 
The aims of the present study were to assess the risk of relapse after discontinuation of antiTNF therapy, to identify the factors associated with relapse, to know the rate of response to retreatment with the same anti-TNF drug after relapsing, and to evaluate the safety of retreatment with these drugs. 


\section{METHODS}

\section{Study population}

The present study was a multicentre, observational, retrospective study conducted at 78 Spanish centres. The study population comprised patients diagnosed with CD or UC who had been treated with anti-TNF agents (infliximab [IFX] or adalimumab [ADA]) to induce remission and in whom these drugs had been discontinued after clinical remission was achieved. The reasons for discontinuation of anti-TNF treatment were as follows: elective decision (by the physician and/or by the patient), onset of adverse events, and early introduction of thiopurines combined with an anti-TNF agent in order to induce clinical remission of IBD in patients who were naïve to immunosuppressive therapy (top-down strategy). The minimum requirement for all patients was to have received induction treatment with anti-TNF drugs. The patients were followed for a minimum of 6 months after stopping treatment. Patients who had been treated with anti-TNF drugs for reasons other than IBD or with less than 6 months of follow-up after discontinuation was excluded. If the patients had more than one attempt to stop the anti-TNF treatment, only the first attempt to discontinue this drug was included in analysis.

\section{Ethical aspects}

The study was approved by the respective institutional ethics review boards, and was conducted according to the Declaration of Helsinki and Good Clinical Practice guidelines.

\section{Data collection}

All clinical, endoscopic, and radiological data were obtained from medical records. The data collected included demographic data, duration of IBD, smoking habits, previous surgery 
for IBD, and previous IBD treatments (eg, immunosuppressants). Clinical, endoscopic, laboratory, and radiological data were collected at 3 different times during follow-up: at discontinuation of the anti-TNF drug, when the patient relapsed (if this occurred), and at the last follow-up visit. It was considered that the patient had an endoscopy or a MRI at the moment of withdrawal if these procedures were performed within 30 days before anti-TNF discontinuation. Information about the response to treatment after re-introduction of anti-TNF therapy in relapsing patients and occurrence of adverse events after reintroduction were also recorded.

Study data were collected and managed using REDCap electronic data capture tools hosted at Asociación Española de Gastroenterología (AEG; www.aegastro.es) ${ }^{18}$. AEG is a non-profit Scientific and Medical Society focused on Gastroenterology, and it provided this service free of charge, with the sole aim of promoting independent investigator driven research. REDCap (Research Electronic Data Capture) is a secure, web-based application designed to support data capture for research studies, providing 1) an intuitive interface for validated data entry; 2) audit trails for tracking data manipulation and export procedures; 3) automated export procedures for seamless data downloads to common statistical packages; and 4) procedures for importing data from external sources.

\section{Definitions}

Clinical remission: For luminal $\mathrm{CD}$, remission was defined as a Harvey-Bradshaw index score $\leq 4$ points $^{19}$. For UC, remission was defined as a partial Mayo score $\leq 2$ points $^{20}$. In the case of perianal disease, remission was defined as the absence of fistula drainage despite gentle finger compression (Fistula Drainage Assessment score) ${ }^{21}$. Given the retrospective nature of the study, Harvey-Bradshaw index and partial Mayo score were estimated after reviewing the medical records. 
Endoscopic inflammation: In the case of luminal CD, endoscopic activity was classified as mild, moderate, severe, or mucosal healing, as judged by the investigators based on the findings in the endoscopy report.

Given the retrospective design of the study, it was not feasible to calculate endoscopic scores based on the endoscopy records. The Rutgeerts index was used to categorize the severity of post-surgical recurrence ${ }^{22}$. Endoscopic inflammation in UC patients was classified using the endoscopic subscore of the Mayo index, that was applied retrospectively to individual patient reports ${ }^{23}$.

Radiological remission: For perianal CD, the disease was considered to be in remission if pelvic magnetic resonance imaging (MRI) demonstrated that the perianal fistulas tracts showed no signs of activity and were without local complications. In the case of luminal CD patients, the disease was considered to be inactive if the abdominal MRI did not show contrast enhancement of the wall, oedema, or ulcers.

Relapse: As this is a retrospective study, relapse was defined as the onset of documented clinical, biochemical, endoscopic, or radiological activity leading to a therapeutic intervention, namely, escalation or modification of medical therapy or surgery for disease control.

Response to re-treatment: In patients with luminal $\mathrm{CD}$, remission was defined as a Harvey-Bradshaw index $\leq 4$ points: a partial response was defined as a decrease $\geq 3$ points from baseline. In fistulising $\mathrm{CD}$, remission was defined as cessation of spontaneous fistula drainage and lack of drainage after gentle finger compression, while a decrease from baseline in the number of open draining fistulae of $\geq 50 \%$ or a reduction in fistula drainage were considered partial response. In UC patients, remission was defined as a partial Mayo score $\leq 2$ points, whereas a decrease of $\geq 3$ points from baseline was considered a partial response. Response to retreatment with anti-TNF therapy was evaluated at 2 time points: 14 weeks 
(initial response) and the end of follow-up (final response).

\section{Statistical analysis}

The descriptive analysis of quantitative variables included the mean and standard deviation or the median and interquartile range, depending on whether the variables were normally distributed or not. For the categorical variables, the percentage and the $95 \%$ confidence intervals (95\% CIs) were provided. Comparisons between means were performed using the $t$ test for independent samples. Categorical variables were compared using the $\chi^{2}$ test and the Fisher exact test or the Wilcoxon rank-sum test according to the distribution of data. Statistical significance was set at $P<0.05$.

Long-term maintenance of remission was estimated using Kaplan-Meier curves. Survival curves assessing the impact of several variables on long-term remission were compared using the log-rank test. A Cox regression model was constructed to identify predictive factors for relapse. All the variables that reached statistical significance in the univariate analysis and those that were considered clinically relevant were included in the multivariate analysis. The dependent variable was the risk of relapse after discontinuation of anti-TNF therapy. The independent variables were: type of IBD (CD and UC), gender, age at discontinuation (included as a continuous variable), surgery due to IBD, current smoking habit, type of antiTNF drug received (IFX or ADA), duration of anti-TNF treatment, reasons for anti-TNF discontinuation (elective discontinuation, discontinuation due to adverse events, and discontinuation as a part of a top-down strategy), and treatment with IMMs after discontinuation of anti-TNF therapy.

The results were expressed as hazard ratios (HRs) with their corresponding 95\% CIs. 


\section{RESULTS}

\section{Study population}

The study population comprised 1,055 patients who discontinued anti-TNF drugs after achieving clinical remission and met the inclusion criteria. The median follow-up time after discontinuation was 19 (6-176) months. The main characteristics of the patients are summarized in table 1. Most patients (74\%) had received IFX. The reasons for discontinuation were elective decision (75\%), adverse events (18\%), and remission after undergoing a top-down strategy $(7 \%)$. The disease duration in patients undergoing a top-down strategy was shorter than in both elective discontinuation and adverse event groups (9.8 months, 11.9 months, and 13.1 months, respectively; $\mathrm{p}<0.0001)$. The median duration of antiTNF therapy in the top-down group was shorter than in the other two groups (4 months, 21 months, and 14 months, respectively; $\mathrm{p}<0.0001$ ).

Seventy-two patients treated with IFX received only induction therapy [elective discontinuation group: 30/719 (4\%) patients; adverse events group: 12/174 (7\%) patients; and top-down group: 30/68 (44\%) patients]. All the patients treated with ADA received induction and maintenance therapy. Endoscopy findings at discontinuation were available in 474 patients (45\%); of these, endoscopy findings were normal (ie, no activity was detected) in 419 $(88 \%)$. In the remaining 55 patients (12\%), endoscopic activity was mild in $38(69 \%)$. After discontinuation of anti-TNF drugs, $68 \%$ of patients received therapy with immunomodulators (IMMs) (thiopurines or methotrexate).

A total of 460 patients had a normal endoscopy or a normal MRI at the moment of antiTNF withdrawal. The main characteristics of this subgroup of patients are summarized in table 2. 


\section{Evolution after discontinuation of anti-TNF therapy}

The incidence of relapse was $18 \%$ per patient-year $(95 \% \mathrm{CI}=17 \%-20 \%)$. The median time to relapse after discontinuation was 11 (1-140) months, and the cumulative incidence of relapse was $44 \%(95 \% \mathrm{CI}=41 \%-46 \%): 15 \%$ at 6 months, $24 \%$ at 1 year, $38 \%$ at 2 years, $46 \%$ at 3 years, and $56 \%$ at 5 years after discontinuation. The cumulative incidence of relapse during follow-up is shown in figure 1a.

\section{Evolution by type of IBD}

In $\mathrm{CD}$ patients, the incidence of relapse was $19 \%$ per patient-year $(95 \% \mathrm{CI}=17-21 \%)$, while in UC patients the relapse rate was $17 \%$ per patient-year $(95 \% \mathrm{CI}=15-20 \%)$. Type of IBD was not associated with the risk of relapse $(\mathrm{p}=0.1)$. The cumulative incidence of relapse by type of IBD is shown in figures $1 \mathrm{~b}$ and $1 \mathrm{c}$.

The incidence rate of relapse was $17 \%$ per patient-year $(95 \% \mathrm{CI}=15-18 \%)$ when the analysis considered only patients receiving IMMs after discontinuation, and 26\% per patientyear $(95 \% \mathrm{CI}=22-30 \%)$ when the analysis considered only patients who did not continue the treatment with IMMs. Among patients who maintained IMMs after discontinuation, the cumulative incidence of relapse was $21 \%$ at 1 year, $35 \%$ at 2 years, $43 \%$ at 3 years, and $53 \%$ at 5 years. From the $32 \%$ of patients who did not receive IMMs after withdrawal, 195 had CD. Of these, $110(56 \%)$ patients relapsed. The incidence rate of relapse in this group of patients was $28 \%$ per patient-year (95\%CI $24-33 \%)$. On the other hand, the incidence rate of relapse in $\mathrm{CD}$ patients who were under IMMs after withdrawal was $17 \%$ per patient-year (95\%CI 15-19\%). Patients who relapsed within 3 months of stopping the anti-TNF therapy (early relapse) were more often female $(64 \%$ vs. $51 \%, \mathrm{p}=0.03)$, and had received less frequently treatment with IMMs after the withdrawal of the anti-TNF $(56 \%$ vs. $68 \%$, p $=$ $0.04)$. 


\section{Evolution in patients in deep remission}

In patients in deep remission, the incidence rate of relapse was $19 \%$ per patient-year (95\%CI, 17-22\%): 19\% per patient-year in CD (95\%CI, 16-22\%), and 19\% per patient-year in UC $(95 \% \mathrm{CI}, 15-24 \%)$. The relapse rate after 1 year of discontinuation was $22 \%$ in CD patients and $20 \%$ in UC patients.

\section{Predictors of relapse after discontinuation of anti-TNF therapy}

The univariate analysis showed that gender, treatment with IMMs after discontinuation of anti-TNF therapy, type of anti-TNF drug received, and reasons for discontinuation (elective discontinuation, discontinuation due to adverse events, and discontinuation as part of a topdown strategy) were the only variables associated with the risk of relapse after discontinuation (Figures 2 and 3). No statistical differences were observed in the risk of relapse after discontinuation between patients who maintained thiopurines and patients who continued methotrexate ( $41 \%$ vs. $45 \%$; $>0.05)$.

In the multivariate analysis (table 3), the variables associated with a higher risk of relapse were treatment with $\mathrm{ADA}$ vs. IFX $(\mathrm{HR}=1.29,95 \% \mathrm{CI}=1.03-1.6)$, elective discontinuation (vs. discontinuation as part of a top-down strategy; $\mathrm{HR}=1.82,95 \% \mathrm{CI}=1.19-2.79$ ), and discontinuation due to adverse events (vs. the discontinuation as part of a top-down strategy; $\mathrm{HR}=1.95,95 \% \mathrm{CI}=1.22-3.12$ ). Treatment with IMMs (vs. no treatment) after discontinuation and older age at discontinuation $(\mathrm{HR}=0.99,95 \% \mathrm{CI}=0.98-0.99)$ were associated with a lower risk of relapse $(\mathrm{HR}=0.7,95 \% \mathrm{CI}=0.57-0.88)$. Gender, type of $\mathrm{IBD}$, current smoking habit, prior surgery related to IBD, duration of anti-TNF treatment, and previous treatment with an anti-TNF drug had no impact on the risk of relapse. 


\section{Predictors of relapse by type of IBD}

A subanalysis was performed in patients with $\mathrm{UC}$ and $\mathrm{CD}$. In UC, none of the factors was statistically significant. In CD, disease localization (colonic vs. ileal) and disease behaviour (stricturing vs. inflammatory) were associated with the risk of relapse. Moreover, the variables that were significant in the general multivariate analysis were also significant in this subanalysis (table 4), adjusted by the duration of anti-TNF treatment.

A sensitivity analysis was performed with the patients who maintained IMMs after discontinuation of anti-TNF. Older age at discontinuation was independently associated with a lower risk of relapse $(\mathrm{HR}=0.98,95 \% \mathrm{CI}=0.97-9.98)$. On the other hand, elective discontinuation (vs. discontinuation as part of a top-down strategy; $\mathrm{HR}=1.6,95 \% \mathrm{CI}=1.06$ 2.51) and discontinuation due to adverse events (vs. the discontinuation as part of a top-down strategy; $\mathrm{HR}=1.9,95 \% \mathrm{CI}=1.14-3.23$ ) were significantly associated with a higher risk of relapse.

The model was also evaluated considering only CD patients who had received the antiTNF agent owing to luminal disease (in comparison with UC), and the type of IBD was not associated with a higher risk of relapse $(\mathrm{HR}=1.03,95 \% \mathrm{CI}=0.79-1.34)$. Furthermore, we repeated the analysis after excluding patients with luminal CD to know whether the risk of relapse was higher among patients who received the anti-TNF drug owing to perianal CD in comparison with UC and observed that the risk was not increased $(\mathrm{HR}=1.04,95 \% \mathrm{CI}=0.77$ $1.41)$.

In a subanalysis, which included the 444 IBD patients who had undergone endoscopic evaluation before discontinuation, and that excluded those with CD in which perianal disease was the indication for anti-TNF therapy, the only factor associated with a higher risk of relapse was older age at discontinuation $(\mathrm{HR}=0.98,95 \% \mathrm{CI}=0.97-0.99)$. Thus, the presence of mucosal lesions in the endoscopy was not associated with a higher risk of relapse after 
discontinuation.

\section{Predictors of relapse in patients in deep remission}

In the univariate analysis performed in the group of $\mathrm{CD}$ patients with clinical remission and mucosal healing, the reasons for discontinuation (elective discontinuation, discontinuation due to adverse events, and discontinuation as part of a top-down strategy) was the only variable associated with the risk of relapse after withdrawal $(p<0.0001)$. In UC patients, disease extension (proctitis, left side colitis and extensive colitis) was the only variable statistically significant $(\mathrm{p}=0.002)$.

In the multivariate analysis, the only variable associated with a higher risk of relapse in CD patients was the discontinuation of anti-TNF treatment due to adverse events (vs. the discontinuation as part of a top-down strategy; $\mathrm{HR}=5.26,95 \% \mathrm{CI}=1.94-14.27$ ), while older age at anti-TNF discontinuation was associated with a lower risk of relapse $(\mathrm{HR}=0.97,95 \%$ $\mathrm{CI}=0.96-0.99)$. Gender, type of IBD, current smoking habit, prior surgery related to IBD, duration of anti-TNF treatment longer than 2 years, treatment with IMMs after anti-TNF discontinuation, and elective discontinuation (vs. discontinuation as a part of top-down strategy) were not associated with the risk of relapse. In UC patients, none of these variables were associated with the risk of relapse.

\section{Retreatment with anti-TNF drugs after relapse}

Of the $467(44 \%)$ patients who relapsed, $310(69 \%)$ were retreated with the same anti-TNF drug, $128(28 \%)$ received another drug, and 14 (3\%) were operated on (12 patients had CD and 2 patients had UC). Of the 310 retreated patients, $78 \%$ received anti-TNF induction therapy. Also, $67 \%(95 \% \mathrm{CI}=61-72 \%)$ of these patients achieved clinical remission after 14 weeks of treatment. At the end of follow-up, $75 \%$ of patients $(95 \% \mathrm{CI}=70-80 \%)$ were in 
clinical remission and $13 \%(95 \% \mathrm{CI}=9-18 \%)$ had a partial response (Figure 4a). Clinical remission was also achieved at the end of follow-up by $79 \%$ of patients $(95 \% \mathrm{CI}=72-85 \%)$ retreated with IFX and $69 \%$ of the patients retreated with ADA $(95 \% \mathrm{CI}=60-77 \%)$.

Eighty-six out of the 310 patients (28\%) restarted anti-TNF in monotherapy. From these patients, $53(62 \%)$ achieved clinical remission, and $16(19 \%)$ had a partial response. Patients who restarted anti-TNF in monotherapy achieved clinical remission less frequently than those who restarted anti-TNF combined with IMMs $(68 \%$ vs. $78 \% ; p=0.08)$. The frequency of allergic reactions was similar among patients who restarted anti-TNF in monotherapy and those who restarted combo therapy $(5.2 \%$ vs. $5.8 \%)$.

\section{Retreatment with anti-TNF drugs after relapse by type of IBD}

Of the $338 \mathrm{CD}$ patients who relapsed, $250(74 \%)$ were retreated with the same anti-TNF, $74(22 \%)$ were treated with another drug, and $14(4 \%)$ were operated on. In the case of UC patients, of the 129 patients who relapsed, 70 (54\%) were retreated with the same anti-TNF, 57 (44\%) received another drug, and $2(2 \%)$ were operated on. Response to retreatment by type of IBD is shown in figure $4 b$.

\section{Retreatment with anti-TNF drugs after relapse in patients in deep remission}

Of the 460 patients in deep remission who discontinued the anti-TNF, 177 relapsed. Of these, $125(71 \%)$ were retreated with the same anti-TNF, $49(28 \%)$ received another drug, and $3(1 \%)$ had surgery. At the end of follow-up, $78 \%(95 \% \mathrm{CI}=70-85 \%)$ of the patients were in clinical remission and 15\% (95\% CI=8-20\%) had a partial response. 


\section{Safety of the retreatment after relapse}

After retreatment, 34 of the total of patients who received an anti-TNF drug (11\%) experienced adverse events. Of these, 16 had infusion reactions, leading to the interruption of treatment in 6 cases. Nine patients presented adverse skin reactions but none of them had to discontinue treatment. Of the 6 patients who developed infections ( 2 pharyngitis, 1 varicella, 1 intra-abdominal abscess, 1 candidal intertrigo, and 1 miliary tuberculosis), 2 had to discontinue treatment because of the infection ( 1 of the patients with pharyngitis and the patient with miliary tuberculosis). Finally, 3 patients experienced other types of adverse events (dilated cardiomyopathy, memory loss, and leukopenia, respectively) and had to discontinue therapy. 


\section{DISCUSSION}

To our knowledge, the cohort analysed in the present study is the largest to date in IBD (1,055 patients, median follow-up of 2.4 years $)$ in which the strategy of discontinuing antiTNF therapy after clinical remission has been evaluated. We found that the incidence of relapse was $18 \%$ per patient-year and that the cumulative incidence of relapse was $44 \%$ per patient-year. These findings confirm the relatively short duration of remission after discontinuation of anti-TNF therapy. Other studies have reported similar relapse rates ${ }^{10,16,24-27}$. The relapse rate 1 year after discontinuation was $24 \%$, which was slightly lower than in other series $^{10,16,28}$, probably because almost all patients in whom endoscopic or radiologic activity had been investigated before stopping anti-TNF drugs had inactive disease. In fact, the relapse rate within 1 year of discontinuation in this group of patients was 14\%. Moreover, endoscopic activity was mild in most of the patients in whom activity was detected (12\%). Consequently, nearly $50 \%$ of the patients in our study stopped anti-TNF therapy after having achieved stable remission.

Experience with follow-up periods longer than 1 year after stopping anti-TNFs is very limited. A very recent meta-analysis of 27 studies reported an overall risk of relapse of $44 \%$ in IBD patients who discontinued anti-TNF agents after achieving clinical remission, whereas the reported risk of relapse in the long term ( $\geq 25$ months) was approximately $50 \%{ }^{14}$. Therefore, it seems that, over time, a relevant proportion of patients who stopped anti-TNF therapy will relapse. However, it is also true that a significant group of patients will maintain remission for a long period after stopping treatment. Accordingly, it is essential to identify the factors associated with risk of relapse.

We found that older age at discontinuation was a predictive factor of a lower risk of relapse, possibly because younger age has been identified as a predictive factor of poor 
outcome, since younger patients often have a more aggressive disease course ${ }^{28}$. Therefore, patients diagnosed with IBD at younger ages often begin anti-TNF treatment sooner than those diagnosed at older ages ${ }^{28}$. Indeed, in a recent study, Papamichael et al. followed $100 \mathrm{CD}$ patients who discontinued IFX upon achieving clinical remission for a median of 10 years and found a risk of relapse of $48 \%{ }^{29}$. Moreover, the authors found that age $\geq 25$ years at diagnosis of IBD was the only independent predictive factor for sustained clinical remission after discontinuation.

In the present study, ADA was associated with a higher relapse rate. For many years, IFX has been the only anti-TNF agent approved for IBD, thus explaining why ADA has been used as the second anti-TNF agent in many patients in whom IFX has previously failed or has lost efficacy. However, in the multivariate analysis, treatment with a previous anti-TNF agent was not associated with a higher risk of relapse after discontinuation. Finally, this finding could be a proxy for undetected variables that were not evaluated and that could be associated with a higher risk of relapse after discontinuation of anti-TNF therapy. Nevertheless, even though the higher risk of relapse after discontinuation of ADA was statistically significant, its magnitude was relatively low $(\mathrm{HR}=1.29,95 \% \mathrm{CI}=1.03-1.6)$ and, therefore, of uncertain clinical relevance.

The top-down strategy (i.e., early introduction of anti-TNF agents combined with thiopurines) is frequently used in patients with moderate to severe IBD and with predictive factors of poor outcome (e.g., younger age at diagnosis, early need for corticosteroids, fistulising phenotype, and perianal disease $)^{30}$. Patients who discontinue anti-TNF therapy after a top-down strategy are usually in stable remission (clinical, endoscopic, radiologic, and biochemical) before stopping therapy. Moreover, the rate of mucosal healing has been reported to be higher after a top-down strategy than with the conventional step-up approach; in addition, the top-down strategy could favour sustained remission ${ }^{4}$. These observations 
might explain why, in our study, patients who electively stopped anti-TNF agents and those who discontinued treatment owing to adverse events presented a significantly higher risk of relapse than those in whom anti-TNF drugs were stopped as part of a top-down strategy. Moreover, patients with a top-down approach were always naïve to IMMs. Consequently, IMMs alone might have been enough to maintain disease remission in some of these patients after stopping anti-TNF therapy. On the contrary, the patients in whom anti-TNF agents had been prescribed for a previous failure to IMMs probably have a higher risk of relapse after stopping anti-TNFs, even when IMMs are maintained. Although our findings seem logical for all the reasons set out above, the small sample size in the top-down group means that our results should be treated with caution.

Almost all the patients who underwent endoscopy before discontinuing anti-TNF drugs had inactive disease, although activity was mild in most of those with active disease. These findings could be explained by the fact that our study reflects routine clinical practice, in which physicians do not usually consider stopping anti-TNF therapy if moderate or severe endoscopic activity is detected, even though the patient is asymptomatic. A recent systematic review showed that the relapse rate was lower when discontinuation of anti-TNF treatment was based on both clinical and endoscopic remission as opposed to clinical remission alone ${ }^{7}$ In this respect, a very recent meta-analysis showed that the incidence of relapse in CD patients, in whom the discontinuation of anti-TNF treatment was based exclusively in clinical remission, was $42 \%$. Similar findings were observed in UC patients. However, if the antiTNF was discontinued in patients in both clinical and endoscopic remission, the relapse rate was $26 \%{ }^{14}$. These findings suggest that mucosal healing is a major factor that should be evaluated when considering withdrawal of anti-TNF therapy. Nevertheless, other studies, including ours, were not able to demonstrate an association between mucosal healing and a lower relapse rate, either in CD and UC patients ${ }^{10,15,17,29,31}$. 
As for type of IBD, although some studies found a non-significant trend for longer remission in patients with $\mathrm{UC}^{11}$, our results showed no differences in the risk of relapse between $\mathrm{CD}$ and UC patients, even when we compared luminal and perianal involvement separately for both CD and UC.

Approximately two-thirds of the patients in this cohort maintained IMMs after stopping anti-TNF drugs, and this was associated with a lower relapse rate. Not receiving concomitant medication with IMMs after stopping anti-TNF treatment has been associated with a higher risk of relapse ${ }^{8,32}$. IMMs enhance the efficacy of anti-TNF therapy, both in the short term and, probably, in the long term; accordingly, concomitant use of anti-TNF drugs with thiopurines, regardless of whether they had previously failed, is generally recommended in clinical practice $^{33}$. This beneficial effect of the IMMs might explain the lower risk of relapse in patients who maintained these drugs after stopping anti-TNF drugs. Finally, we did not find differences in the risk of relapse between patients who maintained thiopurines and those who maintained methotrexate, although the sample of the methotrexate group was too small to draw definitive conclusions.

When we performed a multivariate analysis separately for $\mathrm{CD}$, the factors associated with the risk of relapse were the same as for the overall IBD patients. Moreover, we found that colonic localization (vs. ileal) and stricturing behaviour (vs. inflammatory) were associated with a higher risk of relapse. However, these results should be taken with caution as they are part of a sensitivity analysis.

According to our results, retreatment with the same anti-TNF drug in IBD patients who relapsed after discontinuation was quite effective, inducing remission in $75 \%$ of patients. Even though similar findings have been reported in other studies, none has included as large a sample as the present study ${ }^{7,10,16,34,35}$. The high efficacy of re-initiation of anti-TNF drugs may merely reflect the fact that the patients treated with these drugs are a specific group that were 
previously identified as responders to anti-TNF therapy.

Patients who restarted anti-TNF in monotherapy achieved clinical remission less frequently than those who restarted anti-TNF in combination with IMMs (62\% vs. $78 \%$; $\mathrm{p}=0.08$ ). Although this difference was not statistically significant, there was a trend to a lower response in patients on anti-TNF in monotherapy. Moreover, in our study, the frequency of allergic reactions was similar among patients who restarted anti-TNF in monotherapy and those who restarted combo therapy. These findings are in agreement with data reported by other authors ${ }^{35}$.

Finally, we found that retreatment with the same anti-TNF drug was generally safe. However, 34 patients experienced adverse events which led to withdrawal in 11 patients. For this reason, the decision of stopping anti-TNF therapy should be individualized, and potential consequences (risks and benefits) should always be discussed with the patient.

Our study has several limitations. First, it is retrospective; therefore, the decision to stop anti-TNF agents was based on the subjective criteria of each physician. Moreover, the endoscopic scoring system was applied to individual patients reports, and the clinical activity scales were calculated reviewing medical records. Second, only half of the patients underwent endoscopic assessment at discontinuation. For this reason, and because most of the endoscopic lesions, if any, were mild, it was not possible to accurately determine whether mucosal healing was a predictor of a lower risk of relapse. However, considering that our study reflects daily clinical practice, the fact that a significant proportion of patients had undergone endoscopic evaluation was relevant. Furthermore, although laboratory parameters were collected from medical records, biochemical data were obtained only in a small number of patients.

One of the strengths of the present study is that - to our knowledge - it was based on the largest cohort of patients in whom anti-TNF therapy has been discontinued. In addition, data 
were collected from 78 Spanish hospitals, and the follow-up period was long, with a considerable number of patients followed for more than 5 years.

In conclusion, the results of this large multicentre study showed that approximately half of the patients who discontinued anti-TNF agents because of clinical remission relapse after discontinuation. We found that treatment with ADA, elective discontinuation of anti-TNF drugs, and discontinuation due to adverse events (vs. top-down strategy) were associated with a higher risk of relapse after discontinuation. On the contrary, the maintenance of treatment with IMMs and older age at discontinuation are associated with a lower risk of relapse. Based on these findings, discontinuation of anti-TNF therapy cannot be universally recommended in routine clinical practice. However, it seems that some patients can stop anti-TNF therapy safely and remain in remission for long periods. The decision whether to continue with antiTNF drugs should be taken on an individual basis and discussed with the patient. If the drug is discontinued and the patient with IBD relapses, the response to retreatment with the same anti-TNF is usually effective and safe. 


\section{REFERENCES}

1. Lichtenstein GR, Yan S, Bala M, Blank M, Sands BE. Infliximab maintenance treatment reduces hospitalizations, surgeries, and procedures in fistulizing Crohn's disease. Gastroenterology 2005; 128: 862-869.

2. Pineton de Chambrun G, Peyrin-Biroulet L, Lemann M, Colombel JF. Clinical implications of mucosal healing for the management of IBD. Nat Rev Gastroenterol Hepatol 2010; 7: 1529.

3. Schnitzler F, Fidder H, Ferrante M, Noman M, Arijs I, Van Assche G, et al. Mucosal healing predicts long-term outcome of maintenance therapy with infliximab in Crohn's disease. Inflamm Bowel Dis 2009; 15: 1295-1301.

4. Baert F, Moortgat L, Van Assche G, Caenepeel P, Vergauwe P, De Vos M, et al. Mucosal healing predicts sustained clinical remission in patients with early-stage Crohn's disease. Gastroenterology 2010; 138: 463-468; quiz e410-461.

5. Clarke K, Regueiro M. Stopping immunomodulators and biologics in inflammatory bowel disease patients in remission. Inflamm Bowel Dis 2012; 18: 174-179.

6. D'Haens GR, Panaccione R, Higgins PD, Vermeire S, Gassull M, Chowers Y, et al. The London Position Statement of the World Congress of Gastroenterology on Biological Therapy for IBD with the European Crohn's and Colitis Organization: when to start, when to stop, which drug to choose, and how to predict response? Am J Gastroenterol 2011; 106: 199-212; quiz 213.

7. Gisbert JP, Marin AC, Chaparro M. Systematic review: factors associated with relapse of inflammatory bowel disease after discontinuation of anti-TNF therapy. Aliment Pharmacol Ther 2015; 42: 391-405.

8. Waugh AW, Garg S, Matic K, Gramlich L, Wong C, Sadowski DC, et al. Maintenance of clinical benefit in Crohn's disease patients after discontinuation of infliximab: long-term 
follow-up of a single centre cohort. Aliment Pharmacol Ther 2010; 32: 1129-1134.

9. Molnar T, Farkas K, Miheller P, Nyari T, Szepes Z, Herszenyi L, et al. Is the efficacy of successful infliximab induction therapy maintained for one year lasting without retreatment in different behavior types of Crohn's disease? J Crohns Colitis 2008; 2: 322-326.

10. Molnar T, Lakatos PL, Farkas K, Nagy F, Szepes Z, Miheller P, et al. Predictors of relapse in patients with Crohn's disease in remission after 1 year of biological therapy. Aliment Pharmacol Ther 2013; 37: 225-233.

11. Steenholdt C, Molazahi A, Ainsworth MA, Brynskov J, Ostergaard Thomsen O, Seidelin JB. Outcome after discontinuation of infliximab in patients with inflammatory bowel disease in clinical remission: an observational Danish single center study. Scand J Gastroenterol 2012; 47: 518-527.

12. Farkas K, Lakatos PL, Nagy F, Szepes Z, Miheller P, Papp M, et al. Predictors of relapse in patients with ulcerative colitis in remission after one-year of infliximab therapy. Scand J Gastroenterol 2013.

13. Domenech E, Hinojosa J, Nos P, Garcia-Planella E, Cabre E, Bernal I, et al. Clinical evolution of luminal and perianal Crohn's disease after inducing remission with infliximab: how long should patients be treated? Aliment Pharmacol Ther 2005; 22: 1107-1113.

14. Gisbert JP, Marin AC, Chaparro M. The Risk of Relapse after Anti-TNF Discontinuation in Inflammatory Bowel Disease: Systematic Review and Meta-Analysis. Am J Gastroenterol 2016; 111: 632-647.

15. Molander P, Farkkila M, Salminen K, Kemppainen H, Blomster T, Koskela R, et al. Outcome after discontinuation of TNFalpha-blocking therapy in patients with inflammatory bowel disease in deep remission. Inflamm Bowel Dis 2014; 20: 1021-1028.

16. Louis E, Mary JY, Vernier-Massouille G, Grimaud JC, Bouhnik Y, Laharie D, et al. Maintenance of remission among patients with Crohn's disease on antimetabolite therapy after 
infliximab therapy is stopped. Gastroenterology 2012; 142: 63-70 e65; quiz e31.

17. Brooks AJ, Sebastian S, Cross SS, Robinson K, Warren L, Wright A, et al. Outcome of elective withdrawal of anti-tumour necrosis factor- $\alpha$ therapy in patients with Crohn's disease in established remission. J Crohns Colitis 2015; Epub ahead of print.

18. Harris PA, Taylor R, Thielke R, Payne J, Gonzalez N, Conde JG. Research electronic data capture (REDCap)--a metadata-driven methodology and workflow process for providing translational research informatics support. J Biomed Inform 2009; 42: 377-381.

19. Harvey RF, Bradshaw JM. A simple index of Crohn's-disease activity. Lancet 1980; 1: 514.

20. D'Haens G, Feagan B, Colombel JF, Sandborn WJ, Reinisch W, Rutgeerts P, et al. Challenges to the design, execution, and analysis of randomized controlled trials for inflammatory bowel disease. Gastroenterology 2012; 143: 1461-1469.

21. Present DH, Rutgeerts P, Targan S, Hanauer SB, Mayer L, van Hogezand RA, et al. Infliximab for the treatment of fistulas in patients with Crohn's disease. N Engl J Med 1999; 340: 1398-1405.

22. Rutgeerts P, Geboes K, Vantrappen G, Beyls J, Kerremans R, Hiele M. Predictability of the postoperative course of Crohn's disease. Gastroenterology 1990; 99: 956-963.

23. Schroeder KW, Tremaine WJ, Ilstrup DM. Coated oral 5-aminosalicylic acid therapy for mildly to moderately active ulcerative colitis. A randomized study. N Engl J Med 1987; 317: $1625-1629$.

24. Chauvin A, Le Thuaut A, Belhassan M, Le Baleur Y, Mesli F, Bastuji-Garin S, et al. Infliximab as a bridge to remission maintained by antimetabolite therapy in Crohn's disease: A retrospective study. Dig Liver Dis 2014; 46: 695-700.

25. Armuzzi A, Marzo M, Felice C, De Vincentis F, Andrisani G, Moccio G ea. Long-term scheduled therapy with infliximab in inflammatory bowel disease: a single-centre 
observational study. Gastroenterology 2010; 238 (suppl.1): S-691.

26. Luppino I, Spagnuolo R, Marasco R, Cosco C, Ruggiero G, Cosco V, et al. Withdrawal of infliximab (IFX) after achieving remission: outcome in a cohort of inflammatory bowel disease (IBD) patients. Dig Liver Dis. [Conference abstract: Abstracts of the 19th National Congress of Digestive Diseases]. 2013; 45S: S100-S101.

27. Nuti F, Conte F, Cavallari N, Civitelli F, Aloi M, Alessandri C, et al. Long term efficacy of infliximab in inflammatory bowel disease at a single tertiary center. Dig Liver Dis. [Congress comunication: 17th National Congress SIGENP]. 2010; 42(SUPPL. 5): S326-S327. 28. Gearry RB, Kamm MA, Hart AL, Bassett P, Gabe SM, Nightingale JM. Predictors for developing intestinal failure in patients with Crohn's disease. J Gastroenterol Hepatol 2013; 28: 801-807.

29. Papamichael K, Vande Casteele N, Gils A, Tops S, Hauenstein S, Singh S, et al. Longterm outcome of patients with Crohn's disease who discontinued infliximab therapy upon clinical remission. Clin Gastroenterol Hepatol 2015; 13: 1103-1110.

30. D'Haens G, Baert F, van Assche G, Caenepeel P, Vergauwe P, Tuynman H, et al. Early combined immunosuppression or conventional management in patients with newly diagnosed Crohn's disease: an open randomised trial. Lancet 2008; 371: 660-667.

31. Farkas K, Lakatos PL, Szucs M, Pallagi-Kunstar E, Balint A, Nagy F, et al. Frequency and prognostic role of mucosal healing in patients with Crohn's disease and ulcerative colitis after one-year of biological therapy. World J Gastroenterol 2014; 20: 2995-3001.

32. Bortlík M, Duricova D, Lukas M, Malíčková K, Machkova N, Hrdlicka L, et al. In. 20th United European Gastroenterology Week 2012: P0870.

33. Cabriada JL, Vera I, Domenech E, Barreiro-de Acosta M, Esteve M, Gisbert JP, et al. [Recommendations of the Spanish Working Group on Crohn's disease and ulcerative colitis on the use of anti-tumor necrosis factor drugs in inflammatory bowel disease]. Gastroenterol 
Hepatol 2013; 36: 127-146.

34. Eshuis EJ, Peters CP, van Bodegraven AA, Bartelsman JF, Bemelman W, Fockens P, et al. Ten years of infliximab for Crohn's disease: outcome in 469 patients from 2 tertiary referral centers. Inflamm Bowel Dis 2013; 19: 1622-1630.

35. Domenech E, Zabana Y, Manosa M, Garcia-Planella E, Cabre E, Gassull MA. Infliximab reintroduction is not associated to a higher rate of immune-related adverse effects in patients with inflammatory bowel disease initially treated with a three-infusion induction regimen. $\mathrm{J}$ Clin Gastroenterol 2010; 44: 34-37. 
Guarantor of the article: J.P. Gisbert, MD, $\mathrm{PhD}$.

Specific author contributions: M.J. Casanova, M. Chaparro, and J.P. Gisbert conceived and designed this study. All the authors participated in the collection of data of patients. M.J. Casanova, M. Chaparro, and J.P. Gisbert analyzed and interpreted the results and wrote the manuscript. All the authors critically reviewed the manuscript, and have read and approved the final version of the manuscript.

Financial support: none

Potential competing interests: MJ Casanova: has received research funding from Abbott. Javier P. Gisbert and María Chaparro have served as speakers, consultants, and advisory members for and have received research funding from MSD and Abbvie. E. Domenech has served as a consultant and an advisory board for MSD and Abbott, and has received research funding from MSD and Abbott; F. Gomollón has received fees for conferences and received grants for assistance to scientific meetings from Abbott and MSD; X. Calvet has received grants for research, fees for advisory boards, and lectures from Abott and MSD; S. GarcíaLópez has received grants for assistance to scientific meetings from Abbott, MSD. He has also received consultancy fees from Abbott and MSD; C. Taxonera has served as speaker, consultant, and advisory for Abbott, MSD, and Shire; M. Barreiro-de Acosta has served as a consultant and an advisory board member for MSD and Abbott; M. Esteve has served as an advisory board for Abbott and MSD. All the other authors: none. 
Table 1. Baseline characteristics of the patients.

\begin{tabular}{|c|c|c|c|}
\hline Variables & Total & CD & $\mathbf{U C}$ \\
\hline Type of disease, $\mathrm{n}(\%)$ & $1.055(100)$ & $731(69)$ & $324(31)$ \\
\hline Male, n (\%) & $526(49.9)$ & $349(47.7)$ & $177(54.6)$ \\
\hline Mean age at diagnosis, years (range) & $30(6-76)$ & $29(6-76)$ & $35(9-71)$ \\
\hline Mean age at discontinuation, years (range) & $38(13-82)$ & $37(13-82)$ & $42(16-79)$ \\
\hline Mean age, years (range) & $42(17-85)$ & $41(17-85)$ & $46(17-82)$ \\
\hline Extra-intestinal manifestations, $\mathrm{n}(\%)$ & $287(27)$ & $217(29.9)$ & $70(21.7)$ \\
\hline Current smokers, $\mathrm{n}(\%)$ & $239(24)$ & $203(29)$ & $36(11.4)$ \\
\hline History of abdominal surgery, n (\%) & $248(24)$ & $238(32.8)$ & $10(3.2)$ \\
\hline $\begin{array}{l}\text { Type of anti-TNF therapy, } n(\%) \\
\text {-IFX } \\
\text {-ADA }\end{array}$ & $\begin{array}{l}781(74) \\
274(26)\end{array}$ & $\begin{array}{l}485(66.3) \\
246(33.7) \\
\end{array}$ & $\begin{array}{c}296(91.4) \\
28(8.6) \\
\end{array}$ \\
\hline $\begin{array}{l}\text { Treatment following anti-TNF withdrawal, n (\%) } \\
\text {-Thiopurines } \\
\text {-MTX } \\
\text {-5-ASA } \\
\text {-None }\end{array}$ & $\begin{array}{c}689(65) \\
29(3) \\
149(14) \\
188(18) \\
\end{array}$ & $\begin{array}{l}480(65.7) \\
22(3) \\
65(8.9) \\
164(22.4)\end{array}$ & $\begin{array}{l}209(64.5) \\
7(2.2) \\
84(25.9) \\
24(7.4)\end{array}$ \\
\hline $\begin{array}{l}\text { Endoscopy at the moment of anti-TNF withdrawal, n (\%) } \\
\text {-Endoscopic activity } \\
\text {-Mild activity } \\
\text {-Moderate activity } \\
\text {-Severe activity } \\
\text {-Unknown grade of activity }\end{array}$ & $\begin{array}{l}474(45) \\
55(12) \\
38(69) \\
4(7) \\
2(4) \\
11(20)\end{array}$ & $\begin{array}{l}279(58.9) \\
10(3.6) \\
2(0.7) \\
1(2.5) \\
7(2.5) \\
\end{array}$ & $\begin{array}{c}195(41.1) \\
28(14.4) \\
2(1) \\
1(2.1) \\
4(2.1) \\
\end{array}$ \\
\hline $\begin{array}{l}\text { Montreal location at CD diagnosis, } \mathrm{n}(\%) \\
\text {-L1 (ileal) } \\
\text {-L2 (colonic) } \\
\text {-L3 (ileocolonic) } \\
\text {-L4 (upper gastrointestinal tract) }\end{array}$ & $\begin{array}{c}200(27.4) \\
159(21.7) \\
371(50.7) \\
1(0.2) \\
\end{array}$ & & \\
\hline $\begin{array}{l}\text { Montreal behaviour at CD diagnosis, } \mathrm{n}(\%) \\
\text {-B1 (inflammatory) } \\
\text {-B2 (stricturing) } \\
\text {-B3 (penetrating) } \\
\text {-Unknown }\end{array}$ & $\begin{array}{l}432(59) \\
126(17) \\
161(22) \\
12(2)\end{array}$ & & \\
\hline Perianal disease, $\mathrm{n}(\%)$ & $277(38)$ & & \\
\hline $\begin{array}{l}\text { UC extension, } \mathrm{n}(\%) \\
\text {-Proctitis } \\
\text {-Left side colitis } \\
\text {-Extensive colitis }\end{array}$ & $\begin{array}{c}19(6) \\
108(33) \\
197(61)\end{array}$ & & \\
\hline $\begin{array}{l}\text { CD with MRI at the moment of anti-TNF withdrawal, } n \\
\text {-Radiological activity, } n(\%)\end{array}$ & $\begin{array}{c}88 \\
9(10) \\
\end{array}$ & & \\
\hline
\end{tabular}

CD: Crohn's disease; UC: ulcerative colitis; IMMs: immunomodulators; MTX: methotrexate; 5-ASA: 5aminosalicylates; IFX: infliximab; ADA: adalimumab; MRI: magnetic resonance imaging. 
Table 2. Baseline characteristics of the patients in deep remission at the moment of anti-TNF discontinuation.

\begin{tabular}{|c|c|c|c|}
\hline Variables & Total & CD & $\mathbf{U C}$ \\
\hline Type of disease, $\mathrm{n}(\%)$ & $460(100)$ & $300(65.2)$ & $160(34.8)$ \\
\hline Male, n (\%) & $235(51.1)$ & $143(47.7)$ & $92(58)$ \\
\hline Mean age at diagnosis, years (range) & $31(7-70)$ & $29(7-69)$ & $34(9-70)$ \\
\hline Mean age at discontinuation, years (range) & $38(15-80)$ & $36(15-80)$ & $42(16-74)$ \\
\hline Mean age, years (range) & $42(17-82)$ & $40(17-82)$ & $45(18-75)$ \\
\hline Extra-intestinal manifestations, $\mathrm{n}(\%)$ & $103(22.5)$ & $70(23.5)$ & $33(20.6)$ \\
\hline Current smokers, $\mathrm{n}(\%)$ & $87(19.3)$ & $69(23.6)$ & $18(11.4)$ \\
\hline History of abdominal surgery, $\mathrm{n}(\%)$ & $104(23)$ & $101(66)$ & $3(1.8)$ \\
\hline $\begin{array}{l}\text { Type of anti-TNF therapy, } \mathrm{n}(\%) \\
\text {-IFX } \\
\text {-ADA }\end{array}$ & $\begin{array}{l}335(72.8) \\
125(27.2)\end{array}$ & $\begin{array}{l}189(63) \\
111(37)\end{array}$ & $\begin{array}{c}146(91.3) \\
14(8.8)\end{array}$ \\
\hline Anti-TNF longer than 2 years before withdrawal & $193(45.8)$ & $127(48)$ & $66(43)$ \\
\hline $\begin{array}{l}\text { Reasons to discontinue anti-TNF therapy } \\
\text {-Elective decision } \\
\text {-Top down strategy } \\
\text {-Adverse events }\end{array}$ & $\begin{array}{l}400(87) \\
24(5.2) \\
36(7.8)\end{array}$ & $\begin{array}{l}255(85) \\
20(6.7) \\
25(8.3)\end{array}$ & $\begin{array}{c}145(90.6) \\
4(2.5) \\
11(6.9) \\
\end{array}$ \\
\hline $\begin{array}{l}\text { Treatment following anti-TNF withdrawal, n (\%) } \\
\text {-Thiopurines } \\
\text {-MTX } \\
\text {-5-ASA } \\
\text {-None }\end{array}$ & $\begin{array}{l}345(75) \\
9(2) \\
66(14.3) \\
40(8.7)\end{array}$ & $\begin{array}{l}232(77.3) \\
6(2) \\
23(7.7) \\
39(13)\end{array}$ & $\begin{array}{c}113(70.6) \\
3(1.9) \\
43(26.9) \\
1(0.6)\end{array}$ \\
\hline $\begin{array}{l}\text { Montreal location at CD diagnosis, } \mathrm{n}(\%) \\
\text {-L1 (ileal) } \\
\text {-L2 (colonic) } \\
\text {-L3 (ileocolonic) }\end{array}$ & $\begin{array}{c}74(24.7) \\
78(26) \\
148(49.3)\end{array}$ & & \\
\hline $\begin{array}{l}\text { Montreal behaviour at CD diagnosis, n (\%) } \\
\text {-B1 (inflammatory) } \\
\text {-B2 (stricturing) } \\
\text {-B3 (penetrating) } \\
\text {-Unknown }\end{array}$ & $\begin{array}{c}176(58.7) \\
55(18.3) \\
66(22) \\
3(1) \\
\end{array}$ & & \\
\hline Perianal disease, $\mathrm{n}(\%)$ & $113(37.6)$ & & \\
\hline $\begin{array}{l}\text { UC extension, n }(\%) \\
\text {-Proctitis } \\
\text {-Left side colitis } \\
\text {-Extensive colitis }\end{array}$ & $\begin{array}{l}7(4.4) \\
57(5.6) \\
96(60)\end{array}$ & & \\
\hline
\end{tabular}

CD: Crohn's disease; UC: ulcerative colitis; IMMs: immunomodulators; MTX: methotrexate; 5-ASA: 5aminosalicylates; IFX: infliximab; ADA: adalimumab; MRI: magnetic resonance imaging. 
Table 3. Factors associated with the risk of relapse after discontinuation of anti-TNF therapy in the multivariate analysis.

\begin{tabular}{|c|c|c|c|}
\hline Factors & HR & 95\% CI & P-value \\
\hline $\begin{array}{c}\text { Maintenance of IMMs after } \\
\text { discontinuation }\end{array}$ & 0.70 & $0.57-0.88$ & 0.002 \\
\hline Older age at discontinuation & 0.99 & $0.98-0.99$ & $<0.0001$ \\
\hline $\begin{array}{c}\text { Treatment with ADA (vs. IFX) } \\
\begin{array}{c}\text { Elective discontinuation (vs. } \\
\text { discontinuation for top-down } \\
\text { strategy) }\end{array}\end{array} \quad 1.29$ & $1.03-1.60$ & 0.027 \\
\hline $\begin{array}{c}\text { Discontinuation due to adverse } \\
\text { events (vs. discontinuation as part } \\
\text { of a top-down strategy) }\end{array}$ & 1.95 & $1.19-2.79$ & 0.006 \\
\hline
\end{tabular}

HR: hazard ratio; IMMs: immunomodulators; ADA: adalimumab; IFX: infliximab; CI: confidence interval. 
Table 4. Factors associated with the risk of relapse after discontinuation of anti-TNF therapy in the multivariate analysis in $\mathrm{CD}$.

\begin{tabular}{|c|c|c|c|}
\hline Factors & HR & $95 \% \mathrm{CI}$ & $P$-value \\
\hline $\begin{array}{l}\text { Maintenance of IMMs after } \\
\text { discontinuation* }\end{array}$ & 0.67 & $0.51-0.87$ & 0.003 \\
\hline Older age at discontinuation* & 0.98 & $0.97-0.99$ & 0.001 \\
\hline Treatment with ADA (vs. IFX)* & 1.29 & $1.01-1.66$ & 0.04 \\
\hline $\begin{array}{l}\text { Elective discontinuation (vs. } \\
\text { discontinuation for top-down } \\
\text { strategy)* }\end{array}$ & 1.90 & $1.07-3.37$ & 0.03 \\
\hline $\begin{array}{l}\text { Discontinuation due to adverse } \\
\text { events (vs. discontinuation as part of } \\
\text { a top-down strategy)* }\end{array}$ & 2.33 & $1.27-4.29$ & 0.006 \\
\hline Colonic localization (vs. ileal)* & 1.51 & $1.13-2.02$ & 0.005 \\
\hline $\begin{array}{l}\text { Stricturing behaviour (vs. } \\
\text { inflammatory)* }\end{array}$ & 1.50 & $1.09-2.05$ & 0.01 \\
\hline
\end{tabular}

HR: hazard ratio; IMMs: immunomodulators; ADA: adalimumab; IFX: infliximab; CI: confidence interval.

(*) adjusted by duration of anti-TNF therapy 


\section{Figure legends:}

Figure 1a. Kaplan-Meier curve showing the probability of survival without relapse after discontinuation of anti-TNF therapy for the whole study cohort.

Figure 1b. Kaplan-Meier curve showing the probability of survival without relapse after discontinuation of anti-TNF therapy for Crohn's disease patients.

Figure 1c. Kaplan-Meier curve showing the probability of survival without relapse after discontinuation of anti-TNF therapy for ulcerative colitis patients.

Figure 2. Kaplan-Meier curves showing the risk of relapse in patients treated vs. not treated with immunomodulators after discontinuation of anti-TNF therapy.

Figure 3. Kaplan-Meier curves showing the risk of relapse depending on the reason for discontinuation of anti-TNF therapy.

Figure 4a. Response to the retreatment with the same anti-TNF in patients who relapsed after discontinuing anti-TNF therapy.

Figure 4b. Response to the retreatment with the same anti-TNF at the end of follow-up in Crohn's disease and ulcerative colitis patients who relapsed after discontinuing anti-TNF therapy. 


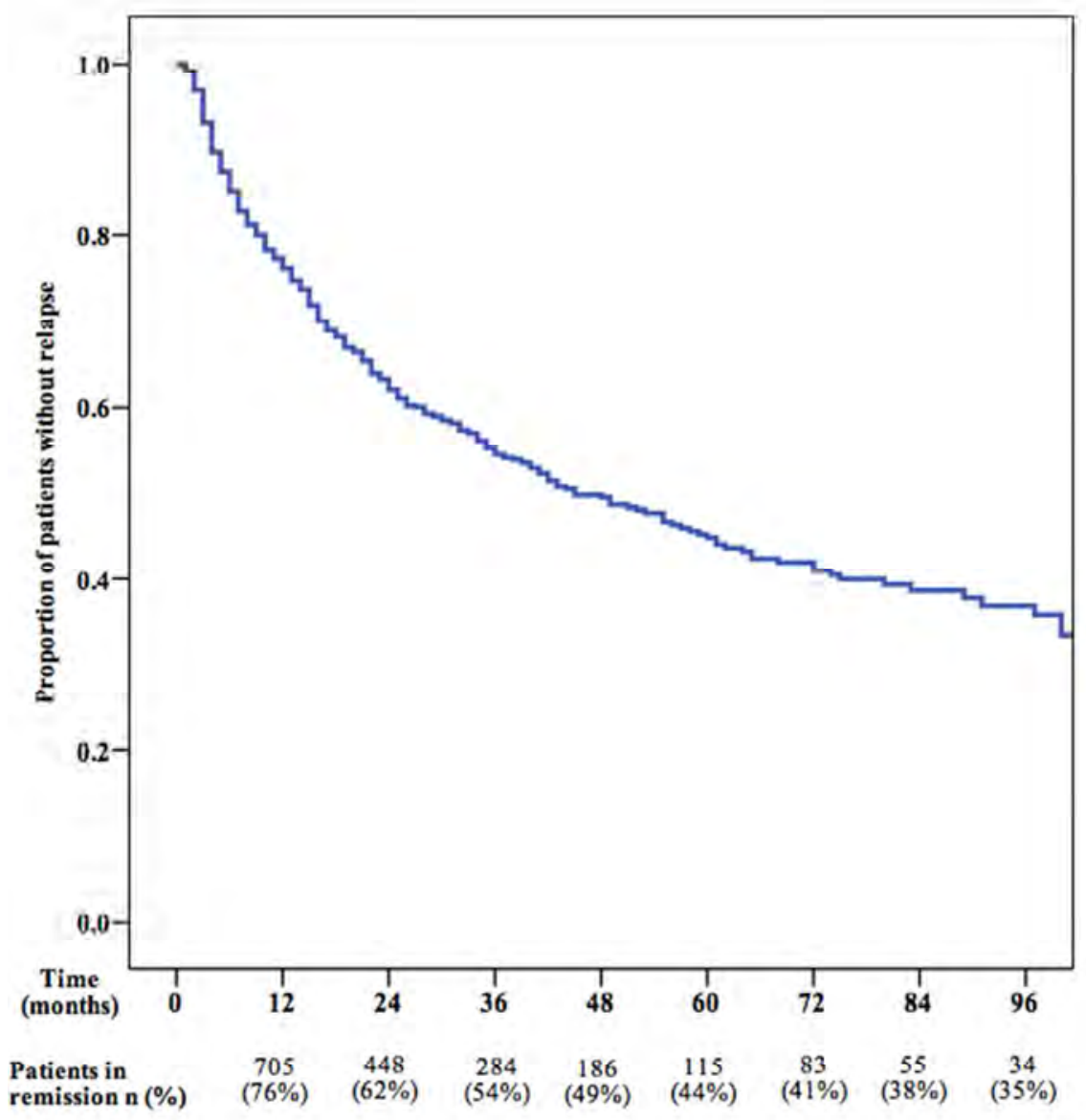

Figure 1a. Kaplan-Meier curve showing the probability of survival without relapse after discontinuation of anti-TNF therapy for the whole study cohort.

$220 \times 219 m m(72 \times 72$ DPI $)$ 


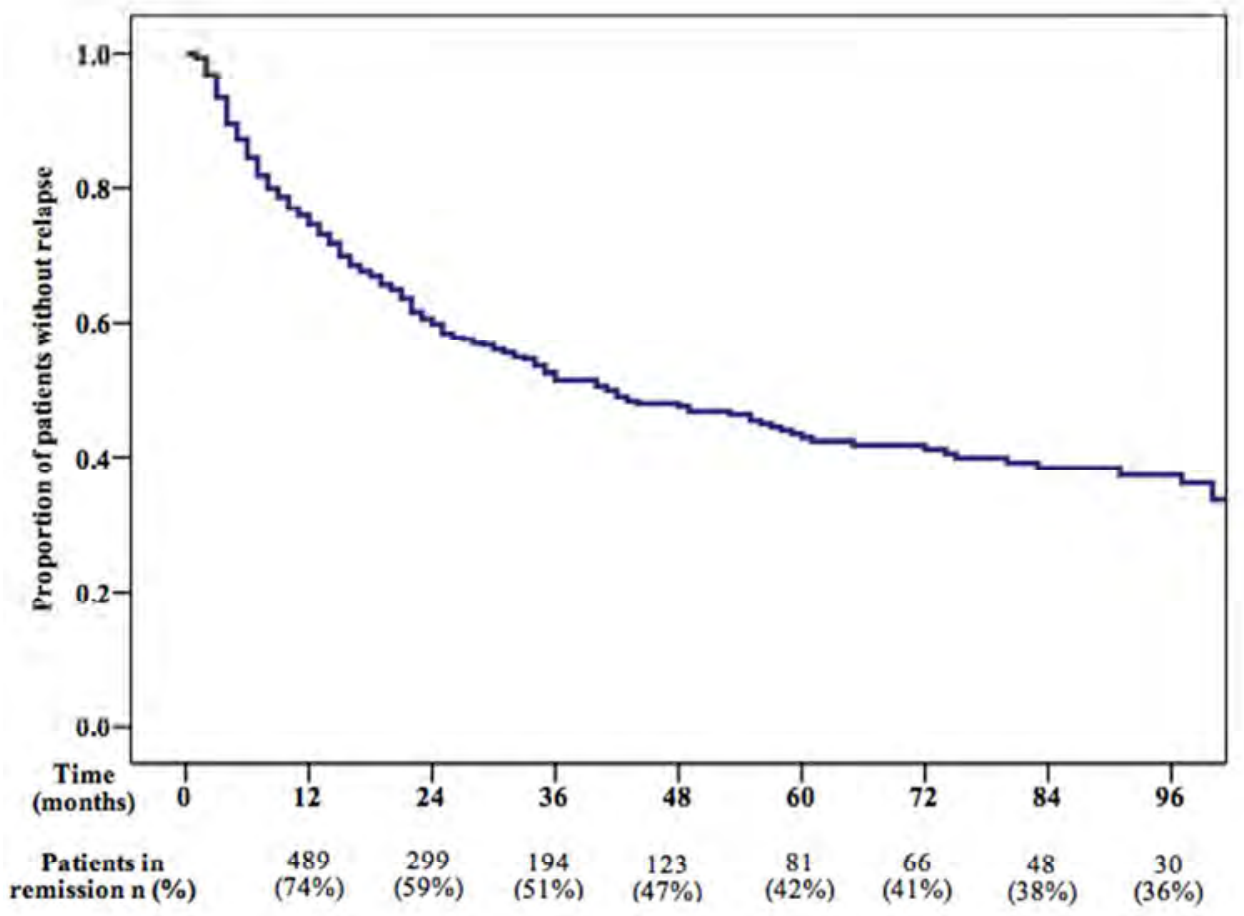

Figure 1b. Kaplan-Meier curve showing the probability of survival without relapse after discontinuation of anti-TNF therapy for Crohn's disease patients. !! +

$219 \times 175 \mathrm{~mm}(72 \times 72 \mathrm{DPI})$ 


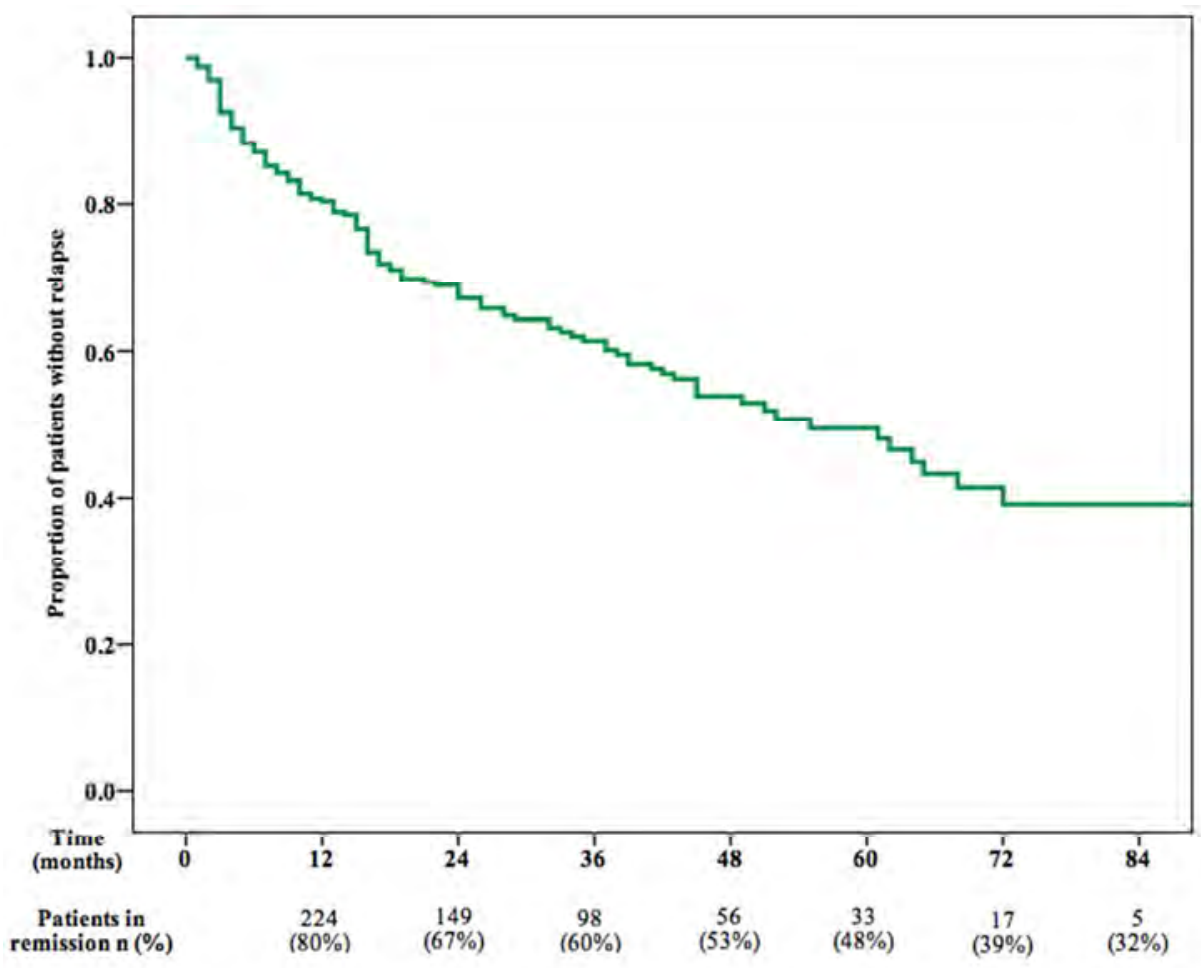

Figure 1c. Kaplan-Meier curve showing the probability of survival without relapse after discontinuation of anti-TNF therapy for ulcerative colitis patients.

$250 \times 186 \mathrm{~mm}(72 \times 72$ DPI $)$ 


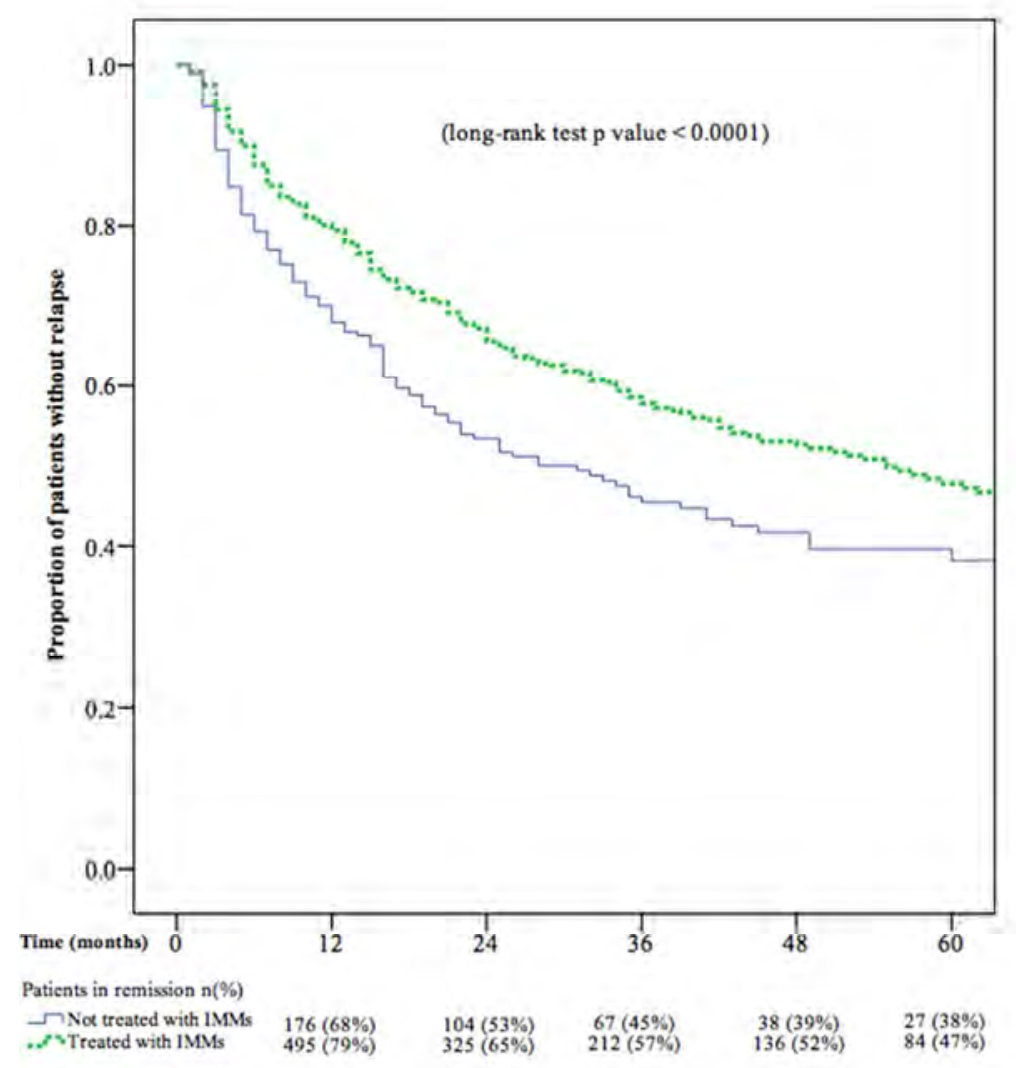

Figure 2. Kaplan-Meier curves showing the risk of relapse in patients treated vs. not treated with immunomodulators after discontinuation of anti-TNF therapy.

$248 \times 212 \mathrm{~mm}(72 \times 72$ DPI $)$ 


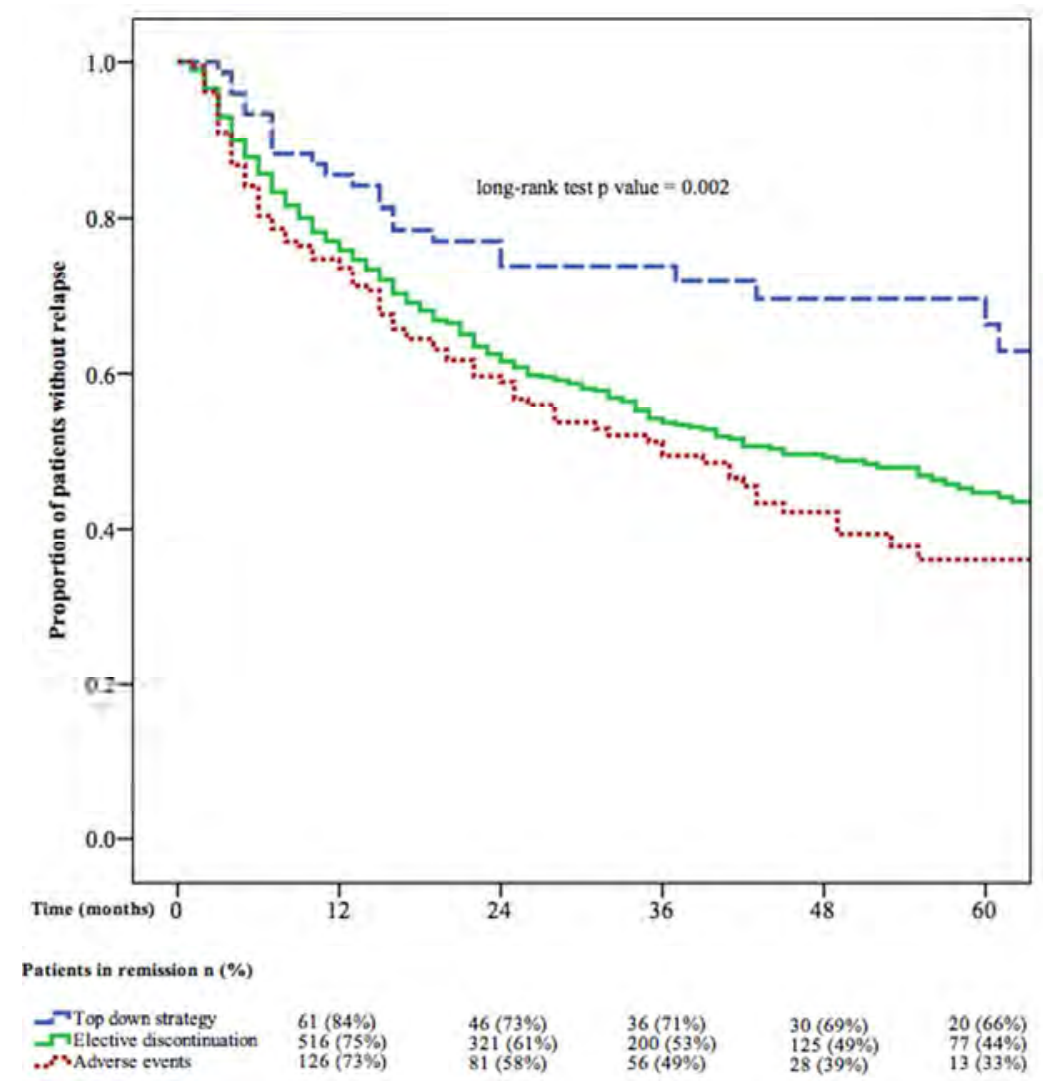

Figure 3. Kaplan-Meier curves showing the risk of relapse depending on the reason for discontinuation of anti-TNF therapy.

$257 \times 213 \mathrm{~mm}(72 \times 72$ DPI $)$ 
Figure 4a. Response to the retreatment with the same anti-TNF in patients who relapsed after discontinuing anti-TNF therapy.

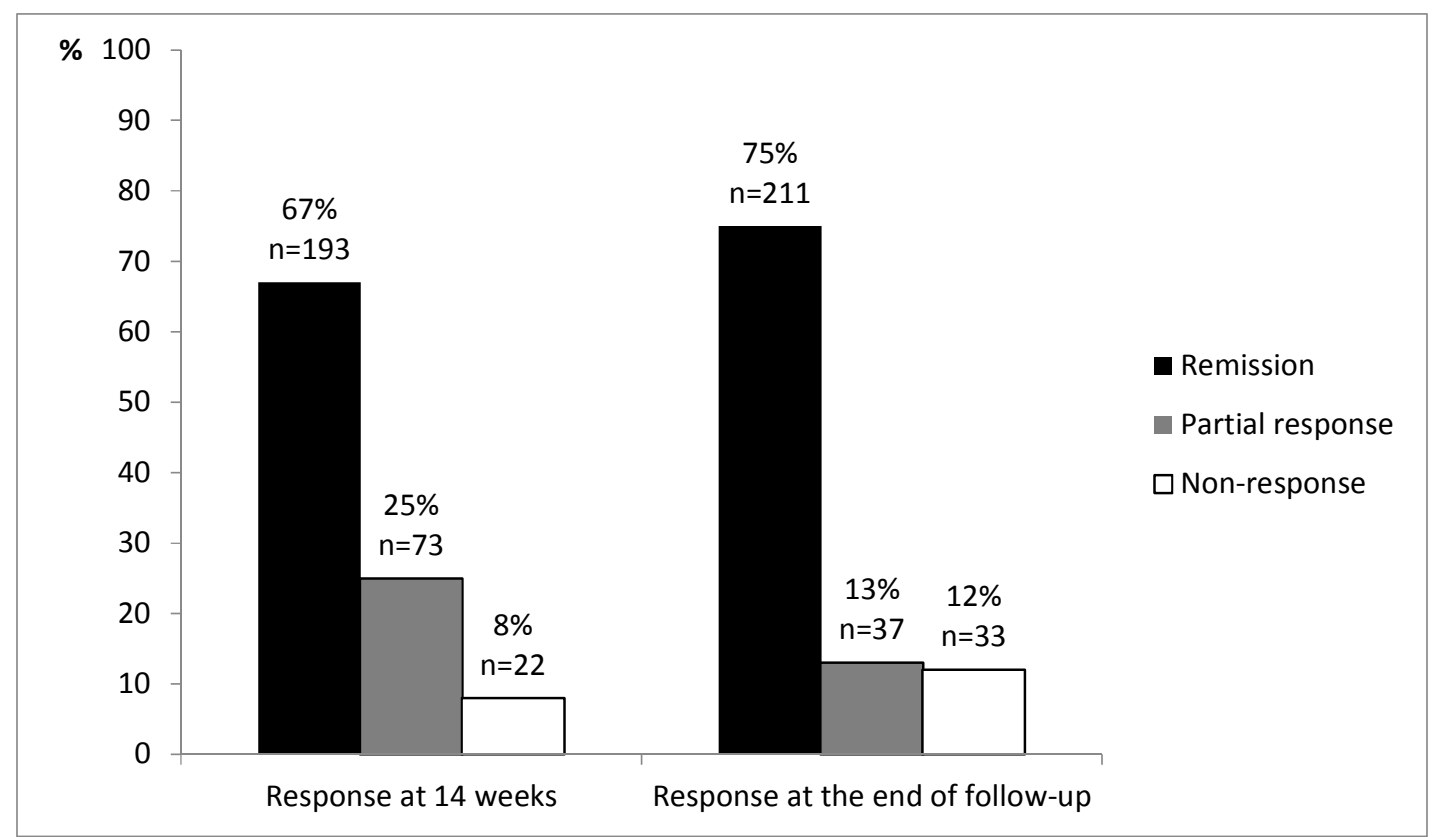


Figure 4b. Response to the retreatment with the same anti-TNF at the end of follow-up in Crohn's disease and ulcerative colitis patients who relapsed after discontinuing anti-TNF therapy.

$\% 100$

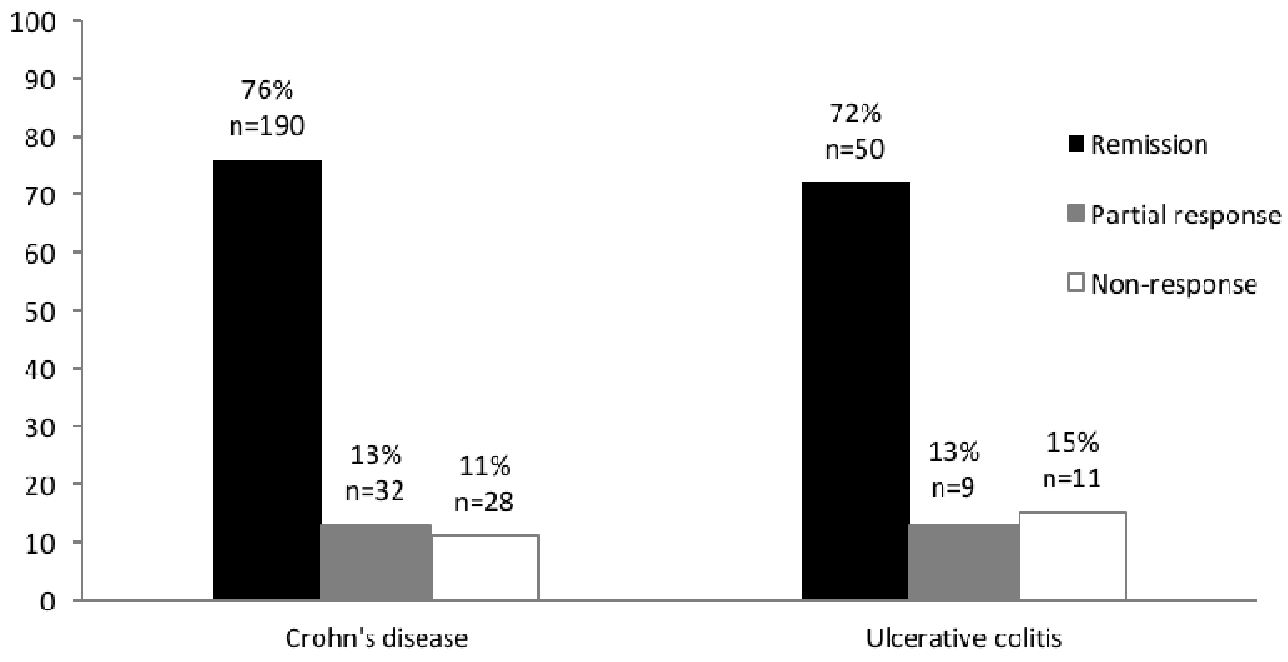

